This manuscript has been authored by UT-Battelle, LLC under Contract No. DE-AC05-00OR22725 with the U.S. Department of Energy. The United States Government retains and the publisher, by accepting the article for publication, acknowledges that the United States Government retains a non-exclusive, paid-up, irrevocable, world-wide license to publish or reproduce the published form of this manuscript, or allow others to do so, for United States Government purposes. The Department of Energy will provide public access to these results of federally sponsored research in accordance with the DOE Public Access Plan (http://energy.gov/downloads/doe-public-access-plan).

\title{
Influence of Processing on the Microstructure and Mechanical Properties of 14YWT
}

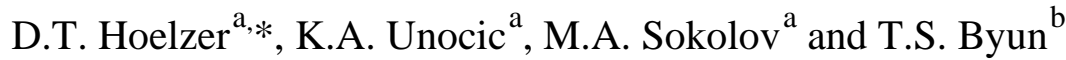 \\ ${ }^{a}$ Oak Ridge National Laboratory \\ ${ }^{\mathrm{b}}$ Pacific Northwest National Laboratory
}

\begin{abstract}
The investigation of the mechanical alloying (MA) conditions for producing the advanced oxide dispersion strengthened (ODS) 14YWT ferritic alloy led to significant improvements in balancing the strength, ductility and fracture toughness properties while still maintaining the salient microstructural features consisting of ultra-fine grains and high concentration of Y-, Tiand O-enriched nanoclusters. The implemented changes to the processing conditions included reducing the contamination of the powder during ball milling, applying a pre-extrusion annealing treatment on the ball milled powder and exploring different extrusion temperatures at $850^{\circ} \mathrm{C}$ (SM170 heat), $1000^{\circ} \mathrm{C}(\mathrm{SM} 185)$ and $1150^{\circ} \mathrm{C}(\mathrm{SM} 200)$. The microstructural studies of the three 14YWT heats showed similarities in the dispersion of nanoclusters and sub-micron size grains, indicating the microstructure was insensitive to the different extrusion conditions. Compared to past 14YWT heats, the three new heats showed lower strength, but higher ductility levels between 25 and $800^{\circ} \mathrm{C}$ and significantly higher fracture toughness values between $25^{\circ} \mathrm{C}$ and $700^{\circ} \mathrm{C}$. The lower contamination levels of $\mathrm{O}, \mathrm{C}$ and $\mathrm{N}$ achieved with improved ball milling conditions plus the slightly larger grain size were identified as important factors for improving the balance in mechanical properties of the three heats of 14YWT.
\end{abstract}

\section{Introduction}

Advanced oxide dispersion strengthened (ODS) ferritic/martensitic steels $(\$ 12 \% \mathrm{Cr})$ and ferritic alloys $(\gtrsim 12 \% \mathrm{Cr})$ are being developed for cladding and core structural materials in several nuclear energy reactor systems due their improved high temperature strength and creep properties and resistance to radiation damage [1-11]. One candidate material being considered for the demanding high-temperature stress and high-neutron dose environments of future Fusion and several Generation IV reactors is the advanced ODS 14YWT ferritic alloy that has been under development at Oak Ridge National Laboratory (ORNL) since the early 2000's [6,8,12]. This alloy attains high strength at room temperature and elevated temperatures due to ultra-fine grains and a high concentration of $\mathrm{Y}_{-}, \mathrm{Ti}-$, and $\mathrm{O}-$-enriched nanoclusters distributed within the

* Corresponding author. Address: 1 Bethel Valley Road, Oak Ridge National Laboratory, Oak Ridge, TN 37831-6115, USA. Tel.: +1 865574 5096. E-mail address: hoelzerd@ornl.gov (D.T. Hoelzer). 
grains and along grain boundaries [6,13-15]. The nanoclusters have been shown to be quite stable at elevated temperatures and during high-dose ion irradiations at elevated temperatures [16-18]. Recently, the nanoclusters present in the PM2 heat of 14YWT have been shown to be associated with the formation of a high concentration of nano-size He bubbles during dual-ion beam irradiations (48 dpa at $650^{\circ} \mathrm{C}$ with 2200 appm He) [19]. However, in light of these promising results on thermal and radiation tolerance of the microstructure, questions remain on whether the high strength properties of 14YWT is the optimum strategy in alloy development for achieving resistance to mechanical property changes caused by high-dose neutron irradiation damage mechanisms at elevated temperatures.

Since 2001, numerous heats of 14YWT have been produced at ORNL, mostly with similar mechanical alloying (MA) processing conditions that had been established early in the research and development program [6]. The primary focus of the early development effort was reducing the grain size of 14YWT to increase the high temperature strength properties and to enhance the total internal interfacial area associated with grain boundaries and the high concentration of nanoclusters to create a high "sink strength" for trapping irradiation induced point defects as well as transmutated He atoms to prevent their migration to grain boundaries to form bubbles. Early studies of 14YWT confirmed the high strength properties (SM4 heat) and the remarkably high fracture toughness of $\sim 178 \mathrm{MPa} \sqrt{\mathrm{m}}$ at room temperature and low fracture toughness transition temperature of $-150^{\circ} \mathrm{C}$ (SM6 heat) that were unaffected by neutron irradiation to $\sim 1.5 \mathrm{dpa}$ at $300^{\circ} \mathrm{C}$ in the HFIR irradiation experiment [6,12,20,21]. However, concern about the high strength properties of 14YWT (SM10 heat) arose after results obtained from high temperature fracture toughness tests showed an abrupt decrease in fracture toughness from $143 \mathrm{MPa} \sqrt{\mathrm{m}}$ at $200^{\circ} \mathrm{C}$ to $72 \mathrm{MPa} \sqrt{\mathrm{m}}$ and $\sim 52 \mathrm{MPa} \sqrt{\mathrm{m}}$ at $300^{\circ} \mathrm{C}$ and $500^{\circ} \mathrm{C}$, respectively [22-23]. These results initiated further development of the MA conditions for producing 14YWT with improved balance of strength, ductility and fracture toughness at room temperature and elevated temperatures without significantly affecting the microstructural features that are responsible for resistance to neutron irradiation damage mechanisms at high doses and temperatures. Therefore, the purpose of this study is to show results of improved MA conditions that have led to an improved balance of mechanical properties without sacrificing the important microstructural characteristics of 14YWT.

\section{Experimental}

\section{Materials and Processing}

Three heats of 14YWT were produced by mechanical alloying (MA). Pre-alloyed powder with nominal composition of $\mathrm{Fe}-14 \mathrm{Cr}-3 \mathrm{~W}-0.4 \mathrm{Ti}$ (wt. \%) was produced by Ar gas atomization by Special Metals (SM). The pre-alloyed powder was blended with $0.3 \% \mathrm{Y}_{2} \mathrm{O}_{3}$ (wt. \%) powder (17$31 \mathrm{~nm}$ crystallite size) that was produced by Nanophase, Inc. Three $1 \mathrm{~kg}$ batches of blended powder were ball milled with a 10:1 ball-to-powder ratio for $40 \mathrm{~h}$ in static Ar gas atmosphere using the high kinetic energy Zoz Simoloyer CM08. After several cycles between vacuum using a rotary vane pump and Ar gas purging, Ar gas was admitted into the chamber, which was then sealed via valves. The three $1 \mathrm{~kg}$ batches of ball milled powder were blended together followed by filling three steel cans with $\sim 0.750 \mathrm{~kg}$ of powder, which were then degassed at $300^{\circ} \mathrm{C}$ in vacuum $\left(<10^{-3} \mathrm{mbar}\right)$ and sealed. A pre-extrusion annealing for $1 \mathrm{~h}$ at $850^{\circ} \mathrm{C}$ was first performed 
on the three sealed cans. The cans were then extruded at three different temperatures, at $850^{\circ} \mathrm{C}$ (SM170 heat), $1000^{\circ} \mathrm{C}$ (SM185 heat) and $1150^{\circ} \mathrm{C}$ (SM200 heat), to produce three heats (SM heats) of 14YWT. The cans were extruded through a rectangular shaped die to form bars. Each bar was cut into three equal length sections and annealed for $1 \mathrm{~h}$ at $1000^{\circ} \mathrm{C}$. Plates of each $\mathrm{SM}$ heat were fabricated by rolling the bar sections either parallel (PR) or normal (NR) to the extrusion direction at $1000^{\circ} \mathrm{C}$ to $\sim 50 \%$ reduction in thickness. Specimens were then fabricated from the plates for characterization studies of the microstructures and mechanical properties. The fabricated specimens were annealed for $1 \mathrm{~h}$ at $1000^{\circ} \mathrm{C}$ prior to the characterization studies.

Chemical analysis was performed on the the extruded samples. The quantitative analysis involved inductively coupled plasma optical emission spectrometry (ICP-OES) for $\mathrm{Al}, \mathrm{Cr}, \mathrm{Fe}, \mathrm{Si}$, $\mathrm{Ti}, \mathrm{W}$ and $\mathrm{Y}$; combustive analysis for $\mathrm{C}$ and $\mathrm{S}$ and inert gas fusion for $\mathrm{O}$ and $\mathrm{N}$. The concentration of solute and interstitial $\mathrm{O}, \mathrm{C}$ and $\mathrm{N}$ elements analyzed for SM170, SM185 and SM200 are shown in Table 1. Most of these solute elements showed good agreement with the chemical analysis results of the atomized powders. However, the 0.04-0.05\%Y (wt. \%) level measured in the extruded samples was significantly lower than the $\sim 0.24 \%$ Y level derived from the addition of $0.3 \% \mathrm{Y}_{2} \mathrm{O}_{3}$ powder. The reason for the low Y levels using ICP-OES is not clear. The $\mathrm{O}$ and $\mathrm{N}$ levels were very similar between the extruded samples, while the $\mathrm{C}$ level was slightly higher in SM170 compared to SM185 and SM200. Microstructural characterization

The microstructural characterization studies that were performed on the SM heats consisted of scanning electron microscopy (SEM), transmission electron microscopy (TEM), energy-filtered

Table 1. Chemical analysis results of SM170, SM185 and SM200.

\begin{tabular}{|c|c|c|c|c|c|c|c|c|c|}
\hline \multirow{2}{*}{ Heat } & \multicolumn{10}{|c|}{ Composition (wt. \%) } \\
\cline { 2 - 11 } & $\mathrm{Fe}$ & $\mathrm{Cr}$ & $\mathrm{W}$ & $\mathrm{Ti}$ & $\mathrm{Y}$ & $\mathrm{S}$ & $\mathrm{O}$ & $\mathrm{C}$ & $\mathrm{N}$ \\
\hline SM170 & 82.70 & 13.85 & 2.08 & 0.26 & 0.04 & 0.003 & 0.094 & 0.036 & 0.012 \\
\hline SM185 & 82.70 & 14.33 & 2.17 & 0.27 & 0.05 & 0.002 & 0.101 & 0.017 & 0.010 \\
\hline SM200 & 82.70 & 14.33 & 2.16 & 0.26 & 0.05 & 0.002 & 0.101 & 0.020 & 0.011 \\
\hline
\end{tabular}

TEM (EFTEM) and scanning transmission electron microscopy (STEM). Metallographic specimens for SEM analysis were prepared from PR plates of the SM heats with the surface in the longitudinal-transverse (L-T) plane, where $\mathrm{L}$ was parallel and $\mathrm{T}$ was normal to the extrusion and rolling directions. The final polishing step for preparation of the metallographic specimens involved colloidal silica. The polished specimens were examined on a JEOL 6500FEG (Field Emission Gun) SEM. For TEM analysis, disk $(\varnothing 3 \times 0.25 \mathrm{~mm})$ specimens were cut by wire electro-discharge machining (EDM) form PR plates in the L-T orientation. The specimens were electro-polished in a Tenupol-3 using an electrolyte solution of $75 \%$ methanol and $25 \%$ nitric acid at $\sim-30^{\circ} \mathrm{C}$. The general microstructural survey of the SM heats was conducted with the polished TEM disks using the Philips CM200 FEG-TEM/STEM. For detailed analysis of the nano-size oxide dispersions, a specimen was lifted-out of the polished region of the TEM disks and thinned by Focused Ion Beam (FIB) milling (Hitachi NB5000 FIB-SEM). The FIB specimens of the three SM heats were examined using the EFTEM technique on the Philips 
CM200 FEG-TEM/STEM. The FIB specimen prepared from SM200 (1150 C extrusion) was analyzed using the JEOL 2200FS aberration-corrected STEM/TEM (ACEM) instrument.

\section{Mechanical properties characterization}

Tensile and fracture toughness testing were performed to evaluate the high-temperature mechanical properties of the three SM heats. For tensile testing, flat sheet miniature SS-J3 tensile (gage dimension: $5 \mathrm{~mm}$ length $\times 1.4 \mathrm{~mm}$ width $\times 0.75 \mathrm{~mm}$ thickness) specimens were fabricated from PR plates of the SM heats by EDM and cutting. The SS-J3 specimens were prepared with the gage parallel to the extrusion direction of the plates. The tensile tests were conducted in air at room temperature $\left(22-25^{\circ} \mathrm{C}\right)$ and at elevated temperatures ranging from $200^{\circ} \mathrm{C}$ to $800^{\circ} \mathrm{C}$ using a strain rate of $10^{-3} \mathrm{~s}^{-1}$ on a MTS HYD-02 machine. The engineering strain was measured by crosshead displacement with no data correction. The uniform elongation (UE) was measured at the point of plastic instability during the tensile test, which pertains to the maximum engineering stress, or ultimate tensile strength, of the stress-strain curves. One tensile test was conducted at each temperature for the $3 \mathrm{SM}$ heats of 14YWT.

The specimen type used for fracture toughness testing was a miniature bend bar (MBB) specimen that had nominal dimensions of $15 \mathrm{~mm}$ in length, $5 \mathrm{~mm}$ in width and $2.5 \mathrm{~mm}$ in thickness with a $1.5 \mathrm{~mm}$ long wire-cut notch and side-grooves of $0.25 \mathrm{~mm}$ in depth in each side. The specimens were fabricated from NR plates of the SM heats in the L-T orientation, i.e. the tensile loading direction near the crack tip parallel to the extrusion direction (L) and crack propagation in the transverse $(\mathrm{T})$ direction. The pre-cracking followed by static J-R fracture resistance testing of the MBB specimens were performed in a MTS servohydraulic testing machine equipped with a high vacuum and high-temperature furnace. A sharp crack tip was produced in the specimen using a nominal cyclic load of $500 \pm 450 \mathrm{~N}$ at $20-30 \mathrm{~Hz}$ until crack growth of $0.5-1 \mathrm{~mm}$ had occurred resulting in a nominal crack length-to-specimen width ratio (a/W) of about 0.46 . The static $\mathrm{J}-\mathrm{R}$ tests were conducted in stroke (displacement) control mode at a cross head speed of $0.005 \mathrm{~mm} / \mathrm{s}$ until the load decreased to $\sim 45 \%$ of maximum load. The analysis for constructing J-R curves was performed using the curve normalization method. The test and analysis followed the procedure described in the ASTM Standard E 1820-01 [24]. Before testing, each specimen was soaked at the target temperature for about 10 min. During high-temperature testing, the temperature was controlled to within $\pm 1^{\circ} \mathrm{C}$ with a nominal vacuum of $\sim 10^{-6}$ torr. The load versus load-line displacement curves with unloading-reloading cycles were recorded and used for analyses to obtain the interim fracture toughness $\left(J_{Q}\right)$ data at $0.2 \mathrm{~mm}$ offset line intersecting the J-R curve. The fracture toughness data in the form of stress intensity factor, $K_{J Q}$, were converted from the $J_{Q}$ data following the procedure described in [23]. Note that these fracture toughness parameters $\left(K_{J Q}\right)$ remain as interim values since some practices with the miniature specimens cannot fully satisfy the ASTM requirements for $\mathrm{K}_{\mathrm{IC}}$.

\section{Results}

\section{Microstructural Characterization}

The microstructures of the SM heats observed by backscattered electron (BSE) imaging are shown in Figure 1. The micrographs show contrast variations for grains in the microstructure due 
to electron channeling effects that are sensitive to grain orientation. The grains were not significantly distorted in the extrusion and rolling directions, which are shown by the arrow in the micrographs. For this reason, the grain size of the SM heats was determined by the mean lineal intercept $(\bar{\lambda})$ method using a line of calibrated length that was randomly oriented on the BSE micrographs [25]. The grain diameter (D) of the SM heats was then estimated by:

$$
D=\frac{3}{2} \bar{\lambda}
$$

This 3/2 conversion factor is from ASTM E112-13 and assumes that the morphology of the grains is spherical. The results from the grain size measurements are shown in Table 2 and showed similar grain sizes in SM170 and SM185, with only small increase of $\sim 0.1 \mu \mathrm{m}$ in SM200. Small particles showing dark contrast were also observed in the microstructures of the three heats. These particles were distributed mostly parallel to the extrusion and rolling direction of the PR plates and are observed in the top section of the BSE micrographs for SM170 (Fig. 1a) and SM185 (Fig. 1b).

Table 2. Grain size measurements for SM170, SM185 and SM200.

\begin{tabular}{|c|c|c|}
\hline Alloy Code & $\begin{array}{c}\text { Mean Lineal } \\
\text { Intercept }(\mu \mathrm{m})\end{array}$ & $\begin{array}{c}\text { Average Grain } \\
\text { Diameter }(\mu \mathrm{m})\end{array}$ \\
\hline SM170 & $0.549 \pm 0.035$ & $0.824 \pm 0.053$ \\
\hline SM185 & $0.536 \pm 0.039$ & $0.804 \pm 0.059$ \\
\hline SM200 & $0.625 \pm 0.061$ & $0.938 \pm 0.092$ \\
\hline
\end{tabular}

Note: $95 \%$ confidence interval $=\bar{x} \pm 2$ S.D., where $\bar{x}$ is the mean and S.D. is standard deviation of the mean.

The general microstructural features observed for the SM heats by bright-field (BF) diffraction contrast imaging are shown in Figures 2 . The analysis showed the presence of a low density of resolvable particles, i.e. $>5-8 \mathrm{~nm}$, non-uniformly distributed in the grain matrix and on high angle grain boundaries (HAGB). Particles below this size range were not resolved with great confidence by diffraction contrast imaging. The phase identification of the larger particles was investigated by HAADF STEM. The results obtained for a particle observed on a grain boundary in SM200 is shown in Figure 3. The lattice fringes associated with the particle (Fig. 3a) indicated that it was $\sim 8 \mathrm{~nm}$ in diameter with a slight aspect ratio. The analysis of the fast Fourier transform (FFT) pattern (Fig. 3b) obtained from the HAADF STEM image showed that it was consistent with the $<001>$ zone axis of the $\mathrm{Y}_{2} \mathrm{Ti}_{2} \mathrm{O}_{7}$ pyrochlore phase $(\mathrm{Fd} 3 \mathrm{~m}$ space group; $\mathrm{a}=1.0095 \mathrm{~nm})$. This result suggests that many of the larger resolvable particles observed in the microstructure of the SM heats may also possess the pyrochlore crystal structure. The BF analysis revealed a relatively low dislocation density in the three SM heats. However, the dislocations were mostly associated with low angle grain boundaries (LAGB) forming sub-grain structures. The sub-grains were observed by termination of bend contours at LAGB, such as the ones pointed to in Figures 2a (SM170), 2b (SM185) and 2c (SM200).

For oxide particles, i.e. nanoclusters (NC), smaller than $\sim 5 \mathrm{~nm}$ in size, the EFTEM Fe-M jumpratio method was used since this technique has been shown to be very reliable for resolving oxygen-enriched NC in 14YWT [13]. The results obtained from EFTEM analysis of the SM 
heats are shown in Figures 4 (SM170), 5 (SM185) and 6 (SM200). The unfiltered image, Fe-M jump ratio map and $t / \lambda$ thickness map observed in these figures were obtained at the same magnification and representative regions containing at least one grain boundary in each specimen. A high concentration of dark imaging particles are observed in the Fe-M jump-ratio maps, but not in the unfiltered images with the exception of a few large particles in SM200 shown in Figure 6. The Fe-M jump-ratio map was obtained by dividing the drift corrected Fe-M post-edge $(62+/-5 \mathrm{eV})$ image with the pre-edge $(46+/-5 \mathrm{eV})$ image. The contrast is very sensitive to local changes in the $\mathrm{Fe}$ content associated with the particle compared to the surrounding matrix, with the resolution approaching $\sim 1 \mathrm{~nm}$ depending on the specimen thickness [13]. The specimen thickness, $t$, was determined from the $t / \lambda$ image, which was obtained from:

$$
\mathrm{t} / \lambda=\operatorname{In}(\text { unfiltered image/zero-loss image) }
$$

where $\lambda$ is the inelastic scattering mean free path, which for Fe is $\sim 140 \mathrm{~nm}$. The thickness of the analyzed regions in the specimens varied from $\sim 30-55 \mathrm{~nm}$ for SM170 (Fig. 4c), 30-45 $\mathrm{nm}$ for SM185 (Fig. 5c) and >60 nm for SM200 (Fig. 6c). The size of the NC was determined from the Fe M-jump ratio maps by measuring the line intensity histogram at full-width-half-maximum (FWHM). The thickness parameter used in assessing the number density of NC was obtained from the mean and standard deviation measured from the $t / \lambda$ maps. The values obtained for the average size and number density of NC in the SM heats are shown in Table 3. The analysis showed that the NC observed in SM200 (Fig. 6b) appeared to be slightly larger in size and lower in number density compared to those observed in SM170 (Fig. 4b) and SM185 (Fig. 5b). This trend is illustrated in the Fe-M jump-ratio maps by showing resolvable NC with FWHM size of $\sim 2.1 \mathrm{~nm}$ for SM170, 2.8 nm for SM185 and $\sim 3.8 \mathrm{~nm}$ for SM200. The size distribution of the NC was compiled and is shown in Figure 7. The size distributions were similar for SM170 and SM185 in each size range. However, for SM200, there were fewer NC in the 2-3 nm size range and more NC in the larger size ranges up to 7-8 nm compared to SM170 and SM185.

Table 3. The average size and number density of nanoclusters obtained for SM170, SM185 and SM200.

\begin{tabular}{|c|c|c|}
\hline Alloy Code & $\begin{array}{c}\text { Average size } \\
(\mathrm{nm})\end{array}$ & $\begin{array}{c}\text { Number Density } \\
\left(\times 10^{23} \mathrm{~m}^{-3}\right)\end{array}$ \\
\hline SM170 & $2.63 \pm 0.56$ & $1.03 \pm 0.20$ \\
\hline SM185 & $2.53 \pm 0.62$ & $1.25 \pm 0.25$ \\
\hline SM200 & $3.60 \pm 1.06$ & $0.77 \pm 0.34$ \\
\hline
\end{tabular}

Note: $95 \%$ confidence interval $=\bar{x} \pm 2$ S.D., where $\bar{x}$ is the mean and S.D. is standard deviation of the mean.

The Fe-M jump ratio maps revealed details about the distribution of larger $\mathrm{NC}$ and oxide particles on grain boundaries in the three SM heats. By comparing the unfiltered image that shows the location of the grain boundary with the Fe-M jump ratio map to observe the larger NC and oxide particles, the results indicated that grain boundaries existed with and without a dispersion of larger NC and oxide particles in all three SM heats. However, the qualitative assessment showed more grain boundaries that were not decorated with larger $\mathrm{NC}$ and oxide particles in SM185 and SM200 compared to SM170. In Figure 4, several slightly larger NC were 
present on the two grain boundaries observed in SM170. However, only a few large oxide particles, most likely the $\mathrm{Y}_{2} \mathrm{Ti}_{2} \mathrm{O}_{7}$ pyrochlore phase, were observed on the grain boundaries in SM200 (Figure 6) and no visible NC or large oxide particles were observed on the grain boundary in SM185 (Figure 5). In figures 8 and 9, the unfiltered image (a) and Fe-M jump ratio map (b) show additional characteristics of $\mathrm{NC}$ and oxide particle distributions near grain boundaries in SM200 and SM185, respectively. Several grain boundaries are observed in Figure 8 for SM200, of which some are decorated with the larger NC and oxide particles (marked ${ }^{*} 2$ ) while others are denuded of particles (marked ${ }^{\#} 1$ and ${ }^{\#} 3$ ). Several linear trails of larger particles are observed that were either not affiliated with a grain boundary or had formed on a grain boundary that extended into an adjacent grain, i.e. the ${ }^{\#} 2$ grain boundary. The single grain boundary shown in Figure 9 for SM185 was associated with several larger NC and oxide particles, which is in contrast to the denuded grain boundary shown in Figure 5.

\section{Mechanical Properties Characterization}

The stress-strain curves obtained at room temperature (RT) and strain rate of $1 \times 10^{-3} \mathrm{~s}^{-1}$ for the three SM heats are shown in Figure 10. The stress-strain curves of the SM heats are remarkably similar. The stress increases to the yield points of 1020-1070 MPa and then increases with strain to similar values of ultimate tensile strengths of $\sim 1170-1220 \mathrm{MPa}$ with corresponding uniform strains of $\sim 9-10 \%$. After plastic instability denoted by necking of the specimens, the deformation proceeded with decreasing nominal stress with increasing strain until failure, which occurred at similar fracture stresses and total elongations of $\sim 21-24 \%$.

The temperature dependence of the tensile properties for the $\mathrm{SM}$ heats from $\mathrm{RT}\left(25^{\circ} \mathrm{C}\right)$ to $800^{\circ} \mathrm{C}$ is shown in Figure 11. The results indicated that values for the yield (YS) and ultimate tensile (UTS) stresses (Figure 11a) and uniform (UE) and total (TE) elongations (Figure 11b) of the three SM heats were very similar over the temperature range. Compared to tensile properties of previous 14YWT heats, such as the SM10 shown in the Figure 11, the three SM heats showed generally lower strength and higher ductility. The YS and UTS of the three SM heats were all near $\sim 1050 \mathrm{MPa}$ and $\sim 1200 \mathrm{MPa}$, respectively, at RT and decreased with temperature to $\sim 260$ $\mathrm{MPa}$ and $\sim 300 \mathrm{MPa}$, respectively, at $800^{\circ} \mathrm{C}$. The UE and TE of the SM heats were $\sim 8-10 \%$ and $\sim 21-24 \%$, respectively, at RT, which is significantly better than the $\sim 1 \%$ UE and 5\% TE observed for SM10. The changes in UE and TE with increasing temperatures showed similar trends for the three heats : the UE decreased slightly with temperatures while the TE remained nearly constant up to $400-500^{\circ} \mathrm{C}$ and then increased to a peak value near $700^{\circ} \mathrm{C}$. The $\mathrm{UE}$ and $\mathrm{TE}$ for SM10 showed insignificant changes from RT to $500^{\circ} \mathrm{C}$ and increased to a peak at $700^{\circ} \mathrm{C}$.

The high-temperature fracture toughness data $\left(K_{J Q}\right)$ of the three SM heats are shown in Figure 12. For comparison, the high-temperature fracture toughness results obtained for 14YWT-SM10 are also shown in the figure [23]. Values of $K_{J Q}(\mathrm{MPa} \sqrt{\mathrm{m}})$ and $J_{Q}\left(\mathrm{~kJ} / \mathrm{m}^{2}\right)$ obtained at $22^{\circ} \mathrm{C}$, $300^{\circ} \mathrm{C}, 500^{\circ} \mathrm{C}$ and $700^{\circ} \mathrm{C}$ are listed in Table 4. The fracture toughness of the three SM heats showed variations at each test temperature, with the largest variation occurring at $300^{\circ} \mathrm{C}$. The fracture toughness of SM170 and SM185 were consistently higher than those of SM200. However, the fracture toughness of the three SM heats was higher than that of 14YWT-SM10 at all temperatures. For 14YWT-SM10, the fracture toughness decreased significantly between $200-300^{\circ} \mathrm{C}$ and remained low at higher temperatures, while that of SM170 and SM185 showed essentially no decrease up to $500^{\circ} \mathrm{C}$. At $500^{\circ} \mathrm{C}$, the fracture toughness values of the $\mathrm{SM}$ heats 
were significantly higher than that of 14YWT-SM10 by factors of 3 to 4 times. The fracture toughness of the three SM heats decreased at $700^{\circ} \mathrm{C}$. However, although SM200 showed marginally higher fracture toughness compared to 14YWT-SM10, the fracture toughness of SM170 and SM185 were both higher than $100 \mathrm{MPa} \sqrt{\mathrm{m}}$, which can be a benchmark value for fabricable material.

Table 4. Comparison of the fracture toughness values as a function of test temperature.

\begin{tabular}{|c|c|c|c|c|c|c|c|c|}
\hline \multirow{2}{*}{$\begin{array}{c}\text { 14YWT } \\
\text { Heat }\end{array}$} & \multicolumn{2}{|c|}{$22^{\circ} \mathrm{C}$} & \multicolumn{2}{c|}{$300^{\circ} \mathrm{C}$} & \multicolumn{2}{c|}{$500^{\circ} \mathrm{C}$} & \multicolumn{2}{c|}{$700^{\circ} \mathrm{C}$} \\
\cline { 2 - 9 } & $\begin{array}{c}K_{J Q} \\
\mathrm{MPa} \sqrt{\mathrm{m}}\end{array}$ & $\begin{array}{c}J_{Q} \\
\mathrm{~kJ} / \mathrm{m}^{2}\end{array}$ & $\begin{array}{c}K_{J Q} \\
\mathrm{MPa} \sqrt{\mathrm{m}}\end{array}$ & $\begin{array}{c}J_{Q} \\
\mathrm{~kJ} / \mathrm{m}^{2}\end{array}$ & $\begin{array}{c}K_{J Q} \\
\mathrm{MPa} \sqrt{\mathrm{m}}\end{array}$ & $\begin{array}{c}J_{Q} \\
\mathrm{~kJ} / \mathrm{m}^{2}\end{array}$ & $\begin{array}{c}K_{J Q} \\
\mathrm{MPa} \sqrt{\mathrm{m}}\end{array}$ & $\begin{array}{c}J_{Q} \\
\mathrm{~kJ} / \mathrm{m}^{2}\end{array}$ \\
\hline $\mathrm{SM} 170$ & 211.1 & 196.3 & 185.8 & 159.8 & 219.8 & 219.0 & 103.4 & 52.9 \\
\hline $\mathrm{SM} 185$ & 188.3 & 156.2 & 242.2 & 271.3 & 209.8 & 199.5 & 118.1 & 69.1 \\
\hline $\mathrm{SM} 200$ & 179.9 & 142.5 & 133.5 & 82.4 & 172.3 & 134.6 & 63.2 & 19.7 \\
\hline $\mathrm{SM}_{0}[23]$ & 142.5 & 90.0 & 72.0 & 24.5 & 52.5 & 15.4 & 53.7 & 24.2 \\
\hline
\end{tabular}

\section{Discussion}

\section{Processing and Microstructure}

One of the goals of this study was to minimize the contamination of the blended SM (Special Metals) powder $\left(\mathrm{Fe}-14 \mathrm{Cr}-3 \mathrm{~W}-0.4 \mathrm{Ti}+0.3 \% \mathrm{Y}_{2} \mathrm{O}_{3}\right)$ during ball milling. Of the potential contaminants, increases in the interstitial $\mathrm{O}, \mathrm{C}$ and $\mathrm{N}$ levels of the powder during ball milling were considered to have the most detrimental effect on the mechanical properties of 14YWT. To reduce these interstitial contaminants, the initially evacuated milling chamber was filled with high purity Ar gas close to atmospheric pressure after each vacuum cycle in an attempt to displace virtually all air from the chamber followed by ensuring that all milling chamber ports were tightly sealed. Although these are standard practices in ball milling procedures, the milling chamber of the high kinetic energy Simoloyer CM08 is still prone to ingress of air during ball milling due to the Teflon seal design of the rotor blade. However, the chemical analysis results of the three extruded SM heats (Table 1) showed ranges of $\sim 940-1000 \mathrm{O}, \sim 170-360 \mathrm{C}$ and $\sim 100$ $100 \mathrm{~N}$ (wppm), which were considered reasonably low. To support this conclusion, Table 5 shows the approximate $\mathrm{O}, \mathrm{C}$ and $\mathrm{N}$ levels of the Ar gas atomized Special Metals powder for comparing the changes in their levels after ball milling for $40 \mathrm{~h}$ and extrusion between the three SM heats and previous SM11 and SM10 heats of 14YWT. From this table, the results for the three SM heats show that the $\mathrm{O}, \mathrm{C}$ and $\mathrm{N}$ levels are increased during the $40 \mathrm{~h}$ ball milling of powders. The estimated changes in $\mathrm{O}, \mathrm{C}$ and $\mathrm{N}$ were $\sim 400 \mathrm{O}, \sim 30 \mathrm{C}$ and $\sim 70 \mathrm{~N}$ after subtracting $\sim 150 \mathrm{O}, \sim 100 \mathrm{C}$ and $\sim 50 \mathrm{~N}$ present in the Ar gas atomized powder and $\sim 640 \mathrm{O}$ from the addition of 0.3 wt. $\% \mathrm{Y}_{2} \mathrm{O}_{3}$ powder. Only the $\mathrm{O}$ level appeared to decrease after extrusion of the ball milled powder, which may be due to the degassing procedure used in preparation of the extrusion cans. For comparison with these results, the chemical analysis of $40 \mathrm{~h}$ ball milled powder used for producing the SM11 heat showed significantly higher increases of $\sim 1800 \mathrm{O}, \sim 250 \mathrm{C}$ and $\sim 1860$ N. Although chemical analysis was not performed on ball milled powder used for 
producing the SM10 heat of 14YWT, the estimated increases of $\sim 940 \mathrm{O}, \sim 620 \mathrm{C}$ and $\sim 1240 \mathrm{~N}$ from the chemical analysis results of the as-extruded material were also significantly higher than that derived from the three extruded SM heats. Thus, a major reduction in $\mathrm{O}, \mathrm{C}$ and $\mathrm{N}$ contamination was achieved in the SM heats using the ball milling conditions implemented in this study.

The increases in the $\mathrm{O}, \mathrm{C}$ and $\mathrm{N}$ levels caused by ball milling can arise from abrasion between ball media and components of the ball milling unit during high kinetic energy impacts and from air that is present in the chamber during ball milling. Of these sources for contamination, wear from contact between ball media and components of the mill most likely caused the small increases in $\mathrm{C}$ level, which is difficult to avoid. However, increases in the $\mathrm{O}$ and $\mathrm{N}$ levels, for example in the SM11 powder and SM10 heat, most likely come from air that displaces the Ar gas (or other cover gas) in the ball mill chamber. Since O and N are the two most abundant elements by volume in air, both should increase if air is the contamination source. This trend was observed for the SM11 powder and SM10 heat, which had high $\mathrm{O}$ and $\mathrm{N}$ pickup levels, in contrast to the SM powder, which had much lower $\mathrm{O}$ and $\mathrm{N}$ levels after ball milling. Thus, reducing the partial pressure of air in the milling chamber and preventing its ingress during ball milling is very important in controlling the contamination levels of $\mathrm{O}$ and $\mathrm{N}$ in ball milled powders.

The purpose for annealing the ball milled SM powder at $850^{\circ} \mathrm{C}$ for $1 \mathrm{~h}$ was to produce the same grain structure and $\mathrm{NC}$ dispersion in the microstructure to investigate changes that might occur by extruding at higher temperatures of $1000^{\circ} \mathrm{C}(\mathrm{SM} 185)$ and $1150^{\circ} \mathrm{C}(\mathrm{SM} 200)$ compared to $850^{\circ} \mathrm{C}$ (SM170) that may lead to improvements in the mechanical properties of 14YWT. This annealing condition was chosen since it simulated the extrusion condition that has been used for

Table 5. Changes in the O, C and $\mathrm{N}$ levels of Ar gas atomized Special Metals powder after ball milling and extrusion of several 14YWT heats.

\begin{tabular}{|c|c|c|c|c|}
\hline \multirow{2}{*}{ Condition } & \multirow[t]{2}{*}{ Heat } & \multicolumn{3}{|c|}{ Composition (wppm) } \\
\hline & & $\mathrm{O}$ & $\mathrm{C}$ & $\mathrm{N}$ \\
\hline Atomized powder & Special Metals* & 150 & 100 & 50 \\
\hline Ball milled powder & $\operatorname{SM}(170-200)$ & 1184 & 128 & 117 \\
\hline Extruded & SM170 & 938 & 363 & 112 \\
\hline Extruded & SM185 & 1010 & 170 & 100 \\
\hline Extruded & SM200 & 1010 & 196 & 111 \\
\hline Ball milled powder & SM11 & 2590 & 346 & 1911 \\
\hline Extruded & SM10 & 1730 & 650 & 1310 \\
\hline
\end{tabular}

* Composition of Ar gas atomized powder by Special Metals are based on the contract specifications.

producing numerous 14 YWT heats during the past 12 years [6,20,22]. Interestingly, the results showed that the pre-extrusion heat treatment for $1 \mathrm{~h}$ at $850^{\circ} \mathrm{C}$ had little effect on producing changes in the microstructure between the three SM heats. The microstructural comparison based on TEM analysis showed effectively no differences in grain size and NC dispersion between 
SM170 and SM185. For SM200, the results showed a small increase in grain size of $\sim 0.1 \mu \mathrm{m}$ and in average NC size of $\sim 1.1 \mathrm{~nm}$ and a small decrease in number density of $\sim 0.25-0.50 \times 10^{23}$ $\mathrm{m}^{-3}$. It is possible that these small differences could be due to the higher extrusion temperature used for SM200. However, they may also be due in part to the possibility that NCs smaller than $\sim 3.0 \mathrm{~nm}$ were not resolved since the specimen of SM200 was thicker (>60 nm) compared to that of SM170 (30-55 nm) and SM185 (30-45 nm). The NC size distribution (Figure 7) of the three SM heats is consistent with this possibility since no NCs in the 1-2 nm size range and fewer NCs in the 2-3 nm size range were detected compared to SM170 and SM185. For specimen thicknesses of $\mathrm{t} \cong 0.25 \lambda(\sim 35 \mathrm{~nm})$, the smallest detectable NC in 14YWT has been found to be $\sim 2 \mathrm{~nm}$ diameter [13]. This resolution was attainable with the range of specimen thicknesses observed for SM170 and SM185. However, the resolution decreases rapidly with increasing specimen thickness and for $\mathrm{t}>0.5 \lambda(\sim 70 \mathrm{~nm})$ it becomes impossible to reliably image the smallest NC. For SM200, many of the smallest NC could not be resolved since $t \gtrsim 0.45 \lambda$. In order to resolve this issue, attempts were made to thin the lift-out FIB specimen of SM200, but were unsuccessful. Small angle neutron scattering experiments are in progress to help elucidate if any significant changes exist in the size, size distribution and number density of NC between the three SM heats. However, despite the small changes noted above it still is concluded that the fine grain structure and high concentration of $\mathrm{NC}$ that form during the $850^{\circ} \mathrm{C}$ annealing are very resistant to coarsening at the higher extrusion temperatures of $1000^{\circ} \mathrm{C}$ and $1150^{\circ} \mathrm{C}$.

The unusual high-temperature microstructural stability of the SM heats may be understood by considering the nucleation sequence of NCs and their thermal stability. In past studies of 14YWT, it was shown that a high areal number density of NC, and nano-size oxide particles such as $\mathrm{Y}_{2} \mathrm{Ti}_{2} \mathrm{O}_{7}$, were present on grain boundaries $[6,20,22]$. These particles are usually slightly larger in size compared to NCs that nucleated within the grains, indicating that they nucleated heterogeneously on the grain boundaries during extrusion of $14 \mathrm{YWT}$ heats at $850^{\circ} \mathrm{C}$ [15]. The NCs and oxide particles act as Zener pinning obstacles that hinder grain growth [26]. However, the high-temperature stability of ultra-fine grains in 14YWT will depend on the thermal stability of the NCs and nano-size oxide particles. From a study of in-situ SANS analysis of 14YWT, the results showed that NCs exhibited remarkable stability during annealing at temperatures up to $\sim 1400^{\circ} \mathrm{C}$ [16]. These results account for the observations of this study by showing the average size of the NCs did not change appreciably $(<1 \mathrm{~nm}$ dia.) with the extrusion temperatures of $850^{\circ} \mathrm{C}(\mathrm{SM} 170), 1000^{\circ} \mathrm{C}$ (SM185) and $1150^{\circ} \mathrm{C}$ (SM200). This also explains why similar grain sizes were observed for the three SM heats despite using different extrusion temperatures since the qualitative assessment of grain boundaries observed in the three SM heats (Fig.'s 4, 5and 6) showed a mixture of grain boundaries decorated with slightly larger NCs and small oxide particles and absent of these particles.

Although no appreciable differences were observed in the grain sizes of the SM heats, the measured grain sizes were larger than that of previous 14YWT heats. For example, the grain size of SM10 was $160 \mathrm{~nm}$ compared to $824 \mathrm{~nm}$ for SM170 even though both heats were produced with similar mechanical alloying conditions [22]. In general, factors that affect the heterogeneous nucleation of $\mathrm{NC}$ and oxide particles on grain boundaries during high-temperature consolidation of ball milled powder will influence the grain size of the ODS alloy. Depending on the type of ball mill and milling conditions, grain sizes of $<50 \mathrm{~nm}$ can be achieved in ball milled powders of many materials [27]. During consolidation of the ball milled powder at elevated temperatures, 
competition between grain coarsening and heterogeneous nucleation of $\mathrm{NC}$ and small oxide particles on grain boundaries occurs. Since the nucleation rate depends on the microstructural state of the ball milled powder and on the heating rate and temperature used for consolidation. Once a critical areal density of particles forms on grain boundaries, further grain coarsening will be hindered which will establish the grain size of 14YWT. As pointed out, the most distinguishable difference between SM10 and the three SM heats was in the total interstitial O, N and $\mathrm{C}$ levels. In most published studies on ODS ferritic alloys, the research focused on the role of $\mathrm{O}$ on formation of oxide particles instead of the effects of $\mathrm{N}$ and $\mathrm{C}$ concentrations on the microstructure and mechanical properties. However, there have been some observations in studies that showed segregation of $\mathrm{N}$ and $\mathrm{C}$ to grain boundaries in 14YWT $[15,28]$ and to a dislocation in 12YWT [29]. Plus, low enrichment levels of $\mathrm{N}$ and $\mathrm{C}$ were also detected in $\mathrm{NC}$ that were located in the matrix and on grain boundaries in 14YWT [28, 30]. Thus, it seems possible that more extensive segregation of $\mathrm{O}, \mathrm{N}$ and $\mathrm{C}$ to grain boundaries occurred in SM10 during consolidation of ball milled powder that enhanced the formation of $\mathrm{NC}$ and small oxide particles at lower temperatures and/or higher nucleation rates. Either possibility would then result in reaching the critical areal density of $\mathrm{NC}$ and small oxide particles on grain boundaries at an earlier stage of grain coarsening during consolidation, resulting in the much smaller grain size compared to the three SM heats. Although this conjectured mechanism requires further support from detailed microstructural characterization of grain boundaries in ball milled powder and in as extruded material, it nevertheless points to the nucleation rate of $\mathrm{NC}$ and oxide particles on grain boundaries as the dominant factor in accounting for the different grain sizes of the 14YWT heats processed with similar MA conditions.

\section{High-Temperature Tensile Properties}

The tensile properties of the three SM heats showed small variations over the temperature range of $25^{\circ}$ to $800^{\circ} \mathrm{C}$ (Fig. 11). Even the stress-strain curves of the SM heats obtained at room temperature (Fig. 10) showed only small differences in the yield stress and the behavior of flow stress with strain to the ultimate tensile stress and finally to the fracture stress. Of the small changes that were observed in the tensile properties of the three SM heats, there were no trends that could be attributed to differences in the extrusion temperatures. These results are not too surprising due to the microstructural similarities of the three SM heats. Also of interest was the comparison of tensile properties between the three SM heats of this study and previous heats of 14YWT, such as the SM10 heat shown in Figure 11. The results showed much higher tensile strength (YS and UTS), but lower ductility (UE and TE) for the SM10 heat compared to the three SM heats over the entire temperature range. These significant differences in tensile properties are surprising since very similar processing conditions were used to produce the SM heats, especially SM170 which was extruded at $850^{\circ} \mathrm{C}$, and SM10.

The temperature-dependent strengthening mechanisms of 14YWT-SM10 were recently investigated and may provide reasons for the lower strengths of the three SM heats [31]. One obvious difference between the microstructures of SM10 and the SM heats is the grain size. For comparison, the average grain size of SM10 was reported to be $\sim 160 \mathrm{~nm}$ [22], while that determined of the three SM heats varied from $~ 814$ to $938 \mathrm{~nm}$ (Table 2). Thus, grain boundary strengthening may account for much of the differences in strengthening. Other factors based on solid-solution strengthening, dispersed barrier (particle) strengthening and dislocation forest 
hardening may have some effect on the strengthening differences, but most likely not as great as that due to grain size. In terms of solid solution strengthening, the same level of strengthening determined for SM10 is expected for the three SM heats since all these heats were produced with Special Metals (SM) powder. It should be pointed out that the higher O, C and N levels observed for SM10 (Table 5) did not contribute to the temperature-dependent values of solid solution strengthening determined by Kim et al. [22] since they were obtained from HIPed SM powder (Fe-14Cr-3W-0.4Ti) without ball balling followed by annealing at $1100^{\circ} \mathrm{C}$ for $4 \mathrm{~h}$. As was shown in Table 5, the elevated $\mathrm{O}, \mathrm{C}$ and $\mathrm{N}$ levels occur during ball milling of the powder. Since the dispersed barrier strengthening depends on the average size and number density of NC, only small differences in strengthening are expected between the SM heats and SM10. Since the NC in $14 \mathrm{YWT}$ are fairly stable up to $1300^{\circ} \mathrm{C}$ [16], it is likely that the $\mathrm{NC}$ dispersion that formed in the ball milled SM powder after the $850^{\circ} / 1 \mathrm{~h}$ heat treatment was similar in terms of size and number density to the NC dispersions present in the extruded SM heats and SM10. Finally, the contribution of dislocation forest hardening to differences in strengthening between the SM heats and SM10 is difficult to assess since the dislocation density was not determined for the three SM heats and was only determined at room temperature and $700^{\circ} \mathrm{C}$ in $14 \mathrm{YWT}-\mathrm{SM} 10$ [32]. However, some variations in the dislocation densities between the three extruded SM heats are expected due to the use of different extrusion temperatures of $850^{\circ} \mathrm{C}, 1000^{\circ} \mathrm{C}$ and $1150^{\circ} \mathrm{C}$.

The grain boundary strengthening contribution to the yield strength of 14YWT was calculated using the Hall-Petch relationship [31]. The strengthening $\left(\sigma_{\mathrm{hp}}\right)$ due to grain size is:

$$
\sigma_{\mathrm{hp}}=k_{h p} \times d^{-1 / 2}
$$

where $k_{h p}$ is the Hall-Petch parameter and d is the grain size. Values of $k_{h p}$ were calculated from tensile and grain size data for several 14YWT heats by fitting yield strength values as a function of $\mathrm{d}^{-1 / 2}$ [31]. Using the values of $k_{h p}$ as a function of temperature $\left(25\right.$ to $800^{\circ} \mathrm{C}$ ), the $\sigma_{h p}$ was calculated for the three SM heats using the measured grain size (Table 2) and are shown in Table 6. The calculated values of $\sigma_{\mathrm{hp}}$ for SM10 from Kim et al. [31] are also included in the table for comparison. By subtracting the calculated $\sigma_{\text {hp }}$ of the three SM heats from that of SM10 $\left(\Delta \sigma_{\text {hp }}\right)$ the results show that significant reductions in grain boundary strengthening occurred in the SM heats as a result of the larger grain sizes. Nevertheless, the calculated $\sigma_{\text {hp }}$ of the three SM heats still show that a sizable amount of strengthening comes from grain boundaries.

Table 6. Comparison of the calculated $\left(\sigma_{\mathrm{hp}}\right)$ and change $\left(\Delta \sigma_{\mathrm{hp}}\right)$ in grain boundary strengthening between the SM200, SM185 and SM170 heats and SM10 heat of 14YWT.

\begin{tabular}{|l|l|l|l|l|}
\hline \multirow{2}{*}{ Temperature } & \multirow{2}{*}{ SM10 } & SM200 & SM185 & SM170 \\
\cline { 2 - 4 } & &
\end{tabular}




\begin{tabular}{|c|c|c|c|c|c|c|c|}
\hline$\left({ }^{\circ} \mathrm{C}\right)$ & $\begin{array}{c}\sigma_{\mathrm{hp}}(\mathrm{Cal} .) \\
(\mathrm{MPa})\end{array}$ & $\begin{array}{c}\sigma_{\mathrm{hp}}(\mathrm{Cal} .) \\
(\mathrm{MPa})\end{array}$ & $\begin{array}{c}\Delta \sigma_{\mathrm{hp}} \\
(\mathrm{MPa})\end{array}$ & $\begin{array}{c}\sigma_{\mathrm{hp}}(\mathrm{Cal} .) \\
(\mathrm{MPa})\end{array}$ & $\begin{array}{c}\Delta \sigma_{\mathrm{hp}} \\
(\mathrm{MPa})\end{array}$ & $\begin{array}{c}\sigma_{\mathrm{hp}}(\mathrm{Cal} .) \\
(\mathrm{MPa})\end{array}$ & $\begin{array}{c}\Delta \sigma_{\mathrm{hp}} \\
(\mathrm{MPa})\end{array}$ \\
\hline 25 & 845 & 349 & -496 & 377 & -468 & 372 & -473 \\
\hline 400 & 927 & 383 & -544 & 414 & -513 & 409 & -518 \\
\hline 500 & 825 & 341 & -484 & 368 & -457 & 364 & -461 \\
\hline 600 & 623 & 257 & -366 & 278 & -345 & 274 & -349 \\
\hline 700 & 317 & 131 & -186 & 142 & -175 & 140 & -177 \\
\hline 800 & 258 & 106 & -152 & 115 & -143 & 113 & -145 \\
\hline
\end{tabular}

The high density of nanoclusters (NC) present in the three SM heats can also contribute to strengthening. For the NC, it was shown that the dispersed barrier hardening $\left(\sigma_{\mathrm{DB}}\right)$ model gave the best results when compared with the yield strength data of 14YWT-SM10 [31]. This strengthening contribution is:

$$
\Delta \sigma_{D B}=0.8 M \alpha(r) G b / \lambda,
$$

where $M$ is the Taylor factor, $G$ is the shear modulus, $b$ is the magnitude of the Burgers vector, $\lambda$ the mean planar center to center distance between $\mathrm{NC}$ and $\alpha(r)$ is the barrier strength coefficient for the NC, which is given by [33],

$$
\alpha(r)=-0.017+0.374 \log (r / 2 b) .
$$

Table 7 shows the calculated values of $\sigma_{\mathrm{DB}}$ obtained using the average NC particle size and number density that were determined for the three SM heats. The calculated values of $\sigma_{\mathrm{DB}}$ for 14YWT-SM10 from Kim et al. [31] are shown for comparison. For the calculations, the temperature-dependence of $G$ was taken into account as was $\alpha(r)$ since it depended on the differences in average NC particle size of the SM heats: the values of $\alpha(r)$ were 0.192 for SM200, 0.134 for SM185 and 0.141 for SM170. The results confirm that a fair amount of strengthening is due to the NC dispersions in the SM heats. However, after subtracting the calculated $\sigma_{\mathrm{DB}}$ of the SM heats from that of $\operatorname{SM} 10\left(\Delta \sigma_{\mathrm{DB}}\right)$ the results show that a decrease in strengthening from the NC dispersions occurred in the SM heats and that the magnitude in the strengthening decrease was larger for SM185 and SM170 compared to SM200. The reason for this is related to the differences in $\alpha(r)$, which predicted less strengthening for SM185 and SM170 due to the smaller average NC particle size despite the larger number density values compared to SM200 (Table 3). But this assessment depends on the accuracy of the NC particle size and number density measurements, which are affected by the inability to resolve the smallest NC by the TEM imaging methods, including EFTEM, used in this study and the accuracy of the specimen thickness.

Table 7. Comparison of the calculated $\left(\sigma_{\mathrm{DB}}\right)$ and change $\left(\Delta \sigma_{\mathrm{DB}}\right)$ in dispersed barrier strengthening between the SM200, SM185 and SM170 heats and SM10 heat of 14YWT. 


\begin{tabular}{|c|c|c|c|c|c|c|c|}
\hline \multirow{2}{*}{$\begin{array}{c}\text { Temperature } \\
\left({ }^{\circ} \mathrm{C}\right)\end{array}$} & SM10 & \multicolumn{2}{|c|}{ SM200 } & \multicolumn{2}{c|}{ SM185 } & \multicolumn{2}{c|}{ SM170 } \\
\cline { 2 - 8 } & $\begin{array}{c}\sigma_{\mathrm{DB}}(\mathrm{Cal} .) \\
(\mathrm{MPa})\end{array}$ & $\begin{array}{c}\sigma_{\mathrm{DB}}(\mathrm{Cal} .) \\
(\mathrm{MPa})\end{array}$ & $\begin{array}{c}\Delta \sigma_{\mathrm{DB}} \\
(\mathrm{MPa})\end{array}$ & $\begin{array}{c}\sigma_{\mathrm{DB}}(\mathrm{Cal} .) \\
(\mathrm{MPa})\end{array}$ & $\begin{array}{c}\Delta \sigma_{\mathrm{DB}} \\
(\mathrm{MPa})\end{array}$ & $\begin{array}{c}\sigma_{\mathrm{DB}}(\mathrm{Cal} .) \\
(\mathrm{MPa})\end{array}$ & $\begin{array}{c}\Delta \sigma_{\mathrm{DB}} \\
(\mathrm{MPa})\end{array}$ \\
\hline 25 & 178 & 166 & -12 & 123 & -55 & 119 & -59 \\
\hline 400 & 146 & 135 & -11 & 100 & -46 & 96 & -50 \\
\hline 500 & 137 & 126 & -11 & 93 & -44 & 90 & -47 \\
\hline 600 & 128 & 118 & -10 & 87 & -41 & 84 & -44 \\
\hline 700 & 119 & 110 & -9 & 81 & -38 & 78 & -41 \\
\hline 800 & 110 & 101 & -9 & 75 & -35 & 72 & -38 \\
\hline
\end{tabular}

The reason for the lower yield strengths of the three SM heats compared to that of SM10 may be explained by the changes observed in the calculated strengthening contributions of grain boundaries $\left(\Delta \sigma_{\mathrm{hp}}\right)$ and $\mathrm{NC}$ particle dispersions $\left(\Delta \sigma_{\mathrm{DB}}\right)$. The compilation of these changes along with the changes in yield strength $\left(\Delta \sigma_{\mathrm{ys}}\right)$ between the SM heats and the SM10 heat is shown in Table 8. In the table, the values of $\Delta \sigma_{\mathrm{hp}}$ and $\Delta \sigma_{\mathrm{DB}}$ were summed together and the negative values indicate the magnitude of the decrease in strength. The comparison between the calculated values of $\Delta \sigma_{\mathrm{hp}}+\Delta \sigma_{\mathrm{DB}}$ and the measured values of $\Delta \sigma_{\mathrm{ys}}$ show good agreement from $25^{\circ} \mathrm{C}$ to $800^{\circ} \mathrm{C}$. The only exception was the large underestimate of $\Delta \sigma_{\mathrm{hp}}+\Delta \sigma_{\mathrm{DB}}\left(-178 \mathrm{MPa}\right.$ ) compared to $\Delta \sigma_{\mathrm{ys}}$ (-78 $\mathrm{MPa})$ for SM185 at $800^{\circ} \mathrm{C}$. These results indicate that the increase in grain size and slight changes in the NC particle dispersions of the SM heats compared to that of 14YWT-SM10 accounts for most of the decrease in yield strength that was observed. The magnitude of the differences between the $\Delta \sigma_{\mathrm{hp}}+\Delta \sigma_{\mathrm{DB}}$ and $\Delta \sigma_{\mathrm{ys}}$ values ranged from $66 \mathrm{MPa}$ (SM170 at $600^{\circ} \mathrm{C}$ ) to $-91 \mathrm{MPa}\left(\mathrm{SM} 185\right.$ at $800^{\circ} \mathrm{C}$ ). The small amount of strengthening not accounted for by grain size and $\mathrm{NC}$ particle dispersions may be due to small differences in the dislocation density and the interstitial $\mathrm{O}, \mathrm{N}$ and $\mathrm{C}$ levels, which may affect solid solution strengthening.

\section{High-Temperature Fracture Toughness Properties}

The significant improvement in the high-temperature fracture toughness of the three SM heats compared to the SM10 heat (Figure 12) is considered to be a major accomplishment in development of $14 \mathrm{YWT}$ and other ODS $\geq 12 \% \mathrm{Cr}$ ferritic alloys [34-36]. The fracture toughness values $\left(K_{J Q}\right.$ and $\left.J_{0.2}\right)$ of the three SM heats varied with temperature, but were all higher than those of SM10 at room temperature $\left(22^{\circ} \mathrm{C}\right)$ and at elevated temperatures of $300^{\circ} \mathrm{C}, 500^{\circ} \mathrm{C}$ and $700^{\circ} \mathrm{C}$ (Table 4). The highest fracture toughness properties were exhibited by SM170 and $\mathrm{SM} 185$, with values of $K_{J Q}$ close to or greater than $200 \mathrm{MPa} \sqrt{\mathrm{m}}$ from $22-500^{\circ} \mathrm{C}$. Although SM200 showed lower fracture toughness values compared to SM170 and SM185 at all temperatures, the values were still significantly higher than those of SM10 at all temperatures except for $700^{\circ} \mathrm{C}$. Also, the variation in fracture toughness between the three SM heats demonstrates that high-temperature fracture toughness testing was more sensitive to the processing differences than tensile testing. 
Table 8. Comparison of the differences in calculated strengthening from $\Delta \sigma_{\mathrm{hp}}$ and $\Delta \sigma_{\mathrm{DB}}$ and yield strength $\Delta \sigma_{\mathrm{ys}}$ between the SM heats and 14YWT-SM10.

\begin{tabular}{|c|c|c|c|c|c|c|}
\hline \multirow{2}{*}{$\begin{array}{c}\text { Temperature } \\
\left({ }^{\circ} \mathrm{C}\right)\end{array}$} & $\begin{array}{c}\Delta\left(\sigma_{\mathrm{hp}}+\sigma_{\mathrm{DB}}\right) \\
(\mathrm{MPa})\end{array}$ & $\begin{array}{c}\Delta \sigma_{\mathrm{ys}} \\
(\mathrm{MPa})\end{array}$ & $\begin{array}{c}\Delta\left(\sigma_{\mathrm{hp}}+\sigma_{\mathrm{DB}}\right) \\
(\mathrm{MPa})\end{array}$ & $\begin{array}{c}\Delta \sigma_{\mathrm{ys}} \\
(\mathrm{MPa})\end{array}$ & $\begin{array}{c}\Delta\left(\sigma_{\mathrm{hp}}+\sigma_{\mathrm{DB}}\right) \\
(\mathrm{MPa})\end{array}$ & $\begin{array}{c}\Delta \sigma_{\mathrm{ys}} \\
(\mathrm{MPa})\end{array}$ \\
\cline { 2 - 7 } & -508 & -541 & -523 & -531 & -532 & -522 \\
\hline 25 & -555 & -603 & -559 & -568 & -568 & -590 \\
\hline 400 & -495 & -520 & -501 & -491 & -508 & -489 \\
\hline 500 & -376 & -384 & -386 & -400 & -393 & -459 \\
\hline 600 & -195 & -231 & -213 & -210 & -218 & -254 \\
\hline 700 & -161 & -150 & -178 & -87 & -183 & -148 \\
\hline 800 & & & & & & \\
\hline
\end{tabular}

Another distinction demonstrated by the fracture toughness results was the different behavior in the temperature dependence of fracture toughness properties. For SM10, a sudden drop of fracture toughness occurred between $200-300^{\circ} \mathrm{C}$. For the three SM heats, the fracture toughness drops at temperatures above $500^{\circ} \mathrm{C}$. But even at $700^{\circ} \mathrm{C}$, the fracture toughness values of SM170 and SM185 were above $100 \mathrm{MPa} \sqrt{\mathrm{m}}$ at $700^{\circ} \mathrm{C}$; nearly 2 times that of SM10 and SM200. These improvements in fracture toughness compare favorably to other ODS $\geq 12 \% \mathrm{Cr}$ ferritic alloys that have been evaluated using similar high-temperature fracture toughness conditions, such as L-T orientation and precrack a/W ratio of $\sim 0.45-0.5$. Sokolov et al. [34] obtained $K_{J I c}$ values (converted from critical J-integral at the onset of stable crack growth) of $80 \mathrm{MPa} \sqrt{\mathrm{m}}$ at $450^{\circ} \mathrm{C}$ and $53 \mathrm{MPa} \sqrt{\mathrm{m}}$ at $550^{\circ} \mathrm{C}$ for $12 \mathrm{YWT}$, which was an ODS $12 \% \mathrm{Cr}$ ferritic alloy developed in Japan [37]. More recently, the high-temperature fracture toughness properties of ODS $12 \% \mathrm{Cr}$ and $14 \% \mathrm{Cr}$ ferritic alloys were investigated within the EURATOM FP7 GETMAT program and reported by Chaouadi [35] and Chaouadi et al. [36]. For the ODS $12 \% \mathrm{Cr}$ ferritic alloy fabricated by KOBELCO Research Institute in Japan, the crack initiation toughness, $J_{0.2}$ (evaluated at 0.2 $m m$ crack extension), was found to be $15.8 \mathrm{~kJ} / \mathrm{m}^{2}$ at $550^{\circ} \mathrm{C}$ and $31.4 \mathrm{~kJ} / \mathrm{m} 2$ at $650^{\circ} \mathrm{C}$ from the average of two test values [35]. In a separate study, a slightly different $J_{0.2}$ value of $32.5 \mathrm{~kJ} / \mathrm{m}^{2}$ was reported at $650^{\circ} \mathrm{C}$ for the KOBELCO ODS $12 \% \mathrm{Cr}$ ferritic alloy, which corresponded to fracture toughness of $77 \mathrm{MPa} \sqrt{\mathrm{m}}$ in terms of stress intensity factor [36]. The crack initiation toughness was also obtained at the same testing temperatures for the ODS $14 \% \mathrm{Cr}$ ferritic alloy developed at CEA. For this alloy, the $J_{0.2}$ at $550^{\circ} \mathrm{C}$ was $39.8 \mathrm{~kJ} / \mathrm{m}^{2}$, but decreased to values within the range $9.4-21.2 \mathrm{~kJ} / \mathrm{m}^{2}$ in 5 tests conducted at $650^{\circ} \mathrm{C}$ [35]. For comparison, the $J_{0.2}$ values at $500^{\circ} \mathrm{C}$ and $700^{\circ} \mathrm{C}$ for $\mathrm{SM} 170$ were $219.0 \mathrm{~kJ} / \mathrm{m}^{2}$ and $52.9 \mathrm{~kJ} / \mathrm{m}^{2}$, respectively, and for SM185 were $209.8 \mathrm{~kJ} / \mathrm{m}^{2}$ and $69.1 \mathrm{~kJ} / \mathrm{m}^{2}$, respectively. These results indicate that the fracture toughness $\left(K_{J Q}\right.$ and $\left.J_{0.2}\right)$ of $\mathrm{SM} 170$ and $\mathrm{SM} 185$ at $700^{\circ} \mathrm{C}$ is significantly improved when compared with other comparable ODS $12-14 \% \mathrm{Cr}$ ferritic alloys tested at lower temperatures of $550^{\circ} \mathrm{C}$ for $12 \mathrm{YWT}$ and $650^{\circ} \mathrm{C}$ for the KOBELCO ODS $12 \% \mathrm{Cr}$ and CEA ODS $14 \% \mathrm{Cr}$ ferritic alloys. 
Clearly the processing conditions used for producing the three SM heats of 14YWT, in particular SM170 and SM185, were responsible for the significant improvement in high-temperature fracture toughness, but the underlying mechanisms involved are not well understood. Several mechanisms have been postulated for explaining the poor high-temperature fracture toughness of ODS $12-14 \% \mathrm{Cr}$ ferritic alloys. From the fracture surface observations of 14YWT (SM10 heat) in the L-T orientation, the reason for the low fracture toughness at high temperatures was due to the increased propensity for decohesion of grain boundaries and shallow plasticity zone at high temperatures [23]. Although fracture surfaces showed ductile fracture features at high temperatures, the corresponding smoother fracture surfaces indicated that the crack tip propagated through a narrow plasticity layer with little resistance due to low bonding strength between grains. For high-temperature fracture toughness of the KOBELCO ODS $12 \% \mathrm{Cr}$ ferritic alloy, the fracture surface in the L-T orientation showed small crack tip opening displacement with secondary crack formation in the extrusion direction and dimple structure [36]. According to Chaouadi [36], the low fracture toughness at high temperatures was due in part to preferential void nucleation at the interface between the oxide particle and matrix with subsequent coalescence enhanced by the high number density of oxide particles that facilitated very little energy to initiate a crack and prevent its propagation. It was suggested that the possible alignment of oxide particles due to extrusion could help decrease the crack resistance during deformation. In considering these possible mechanisms, the more likely reason for the improvement in high-temperature fracture toughness of the three SM heats is due to enhancing the cohesion energy of grain boundaries rather than the particle-matrix interface of small oxide particles. It is possible that the substantially lower interstitial O, C and N levels of the three SM heats led to lower segregation levels of these elements on grain boundaries that increased the bonding strength between grains at high temperatures. Of the interstitials, the segregation of $\mathrm{O}$ and $\mathrm{N}$ to grain boundaries is considered to have the most detrimental effect. In carbon steels, early studies showed that impact toughness was increased by lowering the $\mathrm{O}$ and $\mathrm{N}$ levels or removing these elements from the bcc Fe lattice by precipitating oxide and nitrides (as well as carbides) [38]. Hondros and Stuart determined from grain boundary energies that no significant adsorption of $\mathrm{O}$ occurs in Fe-3\% Si steel [39]. However, the formation of oxygen-rich NC and oxides on grain boundaries in 14YWT indicate that $\mathrm{O}$ must segregate to grain boundaries. Hondros [40] also showed that $\mathrm{N}$ is surface active in iron and becomes enriched on grain boundaries when it exists in levels greater than the equilibrium values. It was also shown that a greater proportion of $\mathrm{N}$ will reside on grain boundaries in iron when the grain size is ultra-small. Briant et al. [41] showed low fracture energy and intergranular fracture after heat treatments of a 3.5Ni-1.7Cr-0.3C steel that caused $\mathrm{N}$ segregation to grain boundaries and also when nitride particles preferentially formed on grain boundaries. The results of these studies support the role of $\mathrm{O}$ and $\mathrm{N}$ segregation causing the lower cohesive energy of grain boundaries, which results in the intergranular fracture at high temperatures. This would account for the enhanced decohesion of grain boundaries and low fracture toughness at high-temperatures that was observed for SM10 with the higher $\mathrm{O}$ and $\mathrm{N}$ levels. Changes in the cohesion energy of the NC-matrix interface by $\mathrm{N}$ are not likely to be a significant factor in the fracture toughness properties. Although $\mathrm{N}$ has been detected by APT $[28,30]$ to be associated with NC in 14YWT, the small increase of $\mathrm{N}$ in the NC population in SM10 compared to the three SM heats is not expected to have a significant effect on the barrier strength coefficient, which is a measure of the interaction of dislocations and the interface between the $\mathrm{NC}$ and matrix. Nevertheless, the $\mathrm{NC}$ and small oxide particles that 
nucleated on grain boundaries could assist in the intergranular fracture process at high temperatures by the void nucleation mechanism proposed by Chaouadi [36].

Coarse second-phase particles, including inclusions, and their distribution in the microstructure of ODS ferritic alloys can also play a role in the low fracture toughness properties. Inclusions of $\mathrm{Al}_{2} \mathrm{O}_{3}$ observed as stringers parallel to the extrusion direction in MA957 $(14 \% \mathrm{Cr})$ contributed to the low fracture toughness properties over transition temperatures below $25^{\circ} \mathrm{C}$ and up to $100^{\circ} \mathrm{C}$ [42]. It was found that the fracture toughness was the lowest when the $\mathrm{Al}_{2} \mathrm{O}_{3}$ stringers were oriented in the fracture plane lying parallel to the extrusion direction, which was also exasperated by anisotropy in the microstructure due to MA processing. High $\mathrm{C}$ levels can lead to formation of $\mathrm{M}_{23} \mathrm{C}_{6}$ type carbide particles, which were shown to reduce the impact toughness properties of the ODS Eurofer $(9 \% \mathrm{Cr})$, when the carbides formed along grain boundaries [43]. However, neither $\mathrm{Al}_{2} \mathrm{O}_{3}$ inclusions nor $\mathrm{M}_{23} \mathrm{C}_{6}$ carbide particles were factors in the high-temperature fracture toughness properties of the three SM heats due to the low Al ( 200 wppm) and C ( 170360 wppm) levels. In addition, recent results obtained by wide-angle x-ray scattering (WAXS) on the 1-ID beamline at the Advanced Photon Source for the CR4 and SM12d heats of 14YWT showed several peaks associated with $\mathrm{M}_{23} \mathrm{C}_{6}$ for $\mathrm{CR} 4$, but no peaks were detected for SM12d [44]. It should be noted that SM12d was an earlier heat designation that was changed to SM170 in this paper. To account for these observations the chemical analysis results (Table 1 in [44]) showed a higher $\mathrm{C}$ level of 540 wppm C for CR4 compared to $363 \mathrm{C}$ for SM170 (SM12d). But stringers of sub-micron size particles showing dark contrast in BSE images (Figure 1) were observed in the three SM heats (Figure 1). These particles were not identified in this study, but most likely are consistent with $\mathrm{Ti}-(\mathrm{O}, \mathrm{N})$ phase identified in heats of $14 \mathrm{YWT}[6,45,46]$. In addition, high $\mathrm{N}$ levels have also been shown to cause the formation of coarse $\mathrm{Cr}-\mathrm{N}$ particles in an ODS 14Cr ferritic alloy [47]. The results showed that the Ti-(O,N) particles were distributed in the microstructure in the direction parallel to the extrusion and rolling directions in PR plates (Figure 1). Although these particles were located close to grain boundaries in the BSE images, they were distributed over a range of up to $\sim 1 \mu \mathrm{m}$ in the direction normal to the extrusion direction. Plus, cross rolling to produce the NR plates used for fracture toughness testing would most likely have disrupted the spatial alignment of the Ti- $(\mathrm{O}, \mathrm{N})$ stringers in the microstructure. Thus, these observations plus the significant improvement in high-temperature fracture toughness indicate that the $\mathrm{Ti}-(\mathrm{O}, \mathrm{N})$ particles did not have any effect on the fracture process of the SM heats.

It still is uncertain how the different extrusion temperatures led to the improved high-temperature fracture toughness of SM170 and SM185 over that of SM200. Two microstructural observations may be important to account for the subtle variations in fracture toughness. In one case, some grain boundaries were free of $\mathrm{NC}$ and small oxide particles while in the other case, some stringers of the NC and small oxide particles were located in the grains and not bound to grain boundaries. Both observations imply that the $\mathrm{NC}$ and small oxide particles that nucleated on grain boundaries during the $850^{\circ} \mathrm{C}$ annealing of ball milled powder can become disassociated from grain boundaries during extrusion. However, different deformation mechanisms as a function of extrusion temperature may occur in the microstructure of the SM heats during consolidation of ball milled powder. For example, processes involving dynamic recovery may be more dominant at the lower extrusion temperature of $850^{\circ} \mathrm{C}$ while dynamic recrystallization may play a more major role at the highest extrusion temperature of $1150^{\circ} \mathrm{C}$ [48]. Both of these 
deformation processes occur during hot forming, such as extrusion and rolling, and will depend on the alloy, such as crystal structure, stacking fault energy and composition, and the deformation factors, such as stress, temperature and strain rate. Although not shown, the stressstrain curves of the $\mathrm{SM}$ heats at $800^{\circ} \mathrm{C}$, which is close to the $850^{\circ} \mathrm{C}$ extrusion temperature, showed the flow stress saturating with strain after yielding with little work hardening, which is consistent with dynamic recovery processes [48]. During dynamic recovery, the grains become heavily strained with subsequent formation of subgrains, which store energy from immobile dislocations. Since only the temperature of extrusion was increased from $850^{\circ} \mathrm{C}$, there would be increasing chances for dynamic recrystallization processes to occur. In this deformation process, the subgrain structures that develop in grains transform to new grains at a critical strain that can then undergo continuous cycles of recovery and recrystallization. It is envisioned that these cycles may result in different fractions of grain boundaries that become dissociated with $\mathrm{NC}$ and small oxide particles established in the pre-extrusion annealing. How this view could account for the variations in fracture toughness can only be speculated. One distinction between dynamic recovery and recrystallization is that the latter will affect the dislocation density and crystallographic texture of the microstructure. This implies that not altering the texture and dislocation density significantly led to the better fracture toughness properties of SM170 and SM185. However, to confirm this line of reasoning will require quantification of the fraction of grain boundaries free of NC and small oxide particles in each of the SM heats and confirmation of texture differences, especially between the SM170 and SM185 heats and the SM200 heat. In addition, fracture toughness testing on specimens fabricated in the T-L orientation may aid in understanding the role of processing on the fracture toughness of the SM heats at high temperatures. These tests on T-L specimens have been conducted at the same temperatures used on L-T specimens and the results along with those of fractography will be published in the future.

\section{Summary}

Three SM heats of 14YWT were produced that led to significant improvements in the balance of strength, ductility and fracture toughness at high temperatures while maintaining microstructures that consisted of ultra-small grains and high concentration of $\mathrm{Y}-$, $\mathrm{Ti}$ - and O-enriched nanoclusters. The most significant processing variables investigated were the ball milling conditions to lower the undesirable pickup of excess $\mathrm{O}, \mathrm{C}$ and $\mathrm{N}$ in the powder and annealing the ball milled powder at $850^{\circ} \mathrm{C}$ for $1 \mathrm{~h}$ in three separate cans followed by preheating the cans at different extrusion temperatures of $850^{\circ} \mathrm{C}(\mathrm{SM} 170), 1000^{\circ} \mathrm{C}(\mathrm{SM} 185)$ and $1150^{\circ} \mathrm{C}(\mathrm{SM} 200)$. The most notable changes in the microstructures of the three SM heats, compared to past heats of 14YWT, was the reduction in interstitial $\mathrm{O}, \mathrm{C}$ and $\mathrm{N}$ levels and the small increase in the grain sizes. Compared to the SM10 heat of 14YWT, the three new SM heats showed lower strength, but higher ductility levels from 25 to $800^{\circ} \mathrm{C}$. Most of the decrease in the strength of the three SM heats compared to SM10 was attributed to Hall-Petch strengthening caused by the increase in grain size. The three SM heats showed significantly higher fracture toughness values from $25^{\circ} \mathrm{C}$ to $700^{\circ} \mathrm{C}$ compared to SM10. The high temperature fracture toughness properties of SM170 and SM185 were also superior to values obtained for 12YWT and two ODS ferritic alloys developed in the GETMAT programs referred to as the ODS 12\%Cr Kobelco and ODS 14\%Cr CEA alloys. The analysis of the results of this study indicated that lowering the $\mathrm{N}$ level in the three SM heats was most beneficial in improving the fracture toughness at high temperatures. It was proposed 
that lower segregation levels of $\mathrm{O}$ and $\mathrm{N}$ (plus $\mathrm{C}$ ) on grain boundaries in the SM heats enhanced the cohesive energy, or bonding strength, between grains that increased the fracture toughness at temperatures up to $700^{\circ} \mathrm{C}$. However, further research is necessary to acquire a more thorough understanding of the effects of the mechanical alloying conditions on the microstructure and subsequent high-temperature mechanical properties of $14 \mathrm{YWT}$ in order to continue with improvements in development of advance ODS ferritic alloys.

\section{Acknowledgement}

The authors acknowledge G.R. Odette and S.A. Maloy for their valuable discussions with regards to the continued development of the advanced ODS 14YWT ferritic alloy and would like to thank D.C Harper, D.W. Coffey, T. Geer and E.T. Manneschmidt for assistance with the experimental work. Research at Oak Ridge National Laboratory (ORNL) was sponsored by the Office of Nuclear Energy, Science and Technology. Microscopy was supported through a user proposal by ORNL's Center for Nanophase Materials Science (CNMS), which is a U.S. Department of Energy, Office of Science User Facility.

\section{References}

[1] S. Ukai, M. Harada, H. Okada, M. Inoue, S. Nomura, S. Shikakura, K. Asabe, T. Nishida and M. Fujiwara, Journal of Nuclear Materials, Vol. 204, (1993), p. 65-73.

[2] R. Lindau, A. Möslang, M. Schirra, P. Schlossmacher and M. Klimenkov, Journal of Nuclear Materials, Vol. 307-311, (2002), p. 769-772.

[3] S. Ukai and M. Fujiwara, Journal of Nuclear Materials, Vol. 307-311, (2002), p. 749-757.

[4] I.-S. Kim, B.-Y Choi, C.-Y Kang, T. Okuda, P.J. Maziasz and K. Miyahara, ISIJ International, Vol. 43, No. 10, (2003), p. 1640-1646.

[5] S. Ukai and S. Ohtsuka, Energy Materials, Vol. 2, No. 1, (2007), p. 26-35.

[6] D.T. Hoelzer, J. Bentley, M.A. Sokolov, M.K. Miller, G.R. Odette and M.J. Alinger, Journal of Nuclear Materials, Vol. 367-370, (2007), p. 166-172.

[7] Y. de Carlan, J.-L. Bechade, P. Dubuisson, J.-L. Seran, P. Billot, A. Bougault, T. Cozzika, S. Doriot, D. Hamon, J. Henry, M. Ratti, N. Lochet, D. Nunes, P. Olier, T. Leblond and M.H. Mathon, Journal of Nuclear Materials, Vol. 386-388, (2009), p. 430-432.

[8] M.J. Alinger, G.R. Odette and D.T. Hoelzer, Acta Materialia, Vol. 57, (2009), p. 392-406.

[9] N. Baluc, J.L. Boutard, S.L. Dudarev, M. Rieth, J. Brito Correia, B. Fournier, J. Henry, F. Legendre, T. Leguey, M. Lewandowska, R. Lindau, E. Marquis, A. Muñoz, B. Radiguet and Z. Oksiuta, Journal of Nuclear Materials, Vol. 417, (2011), p. 149-153.

[10] A. Kimura, R. Kasada, N. Iwata, H. Kishimoto, C.H. Zhang, J. Isselin, P. Dou, J.H. Lee, N. Muthukumar, T. Okuda, M. Inoue, S. Ukai, S. Ohnuki, T. Fujiwara and T.F. Abe, Journal of Nuclear Materials, Vol. 417, (2011), p. 176-179. 
[11] H. Hadraba, B. Kazimierzak, L. Stratil and I. Dlouhy, Journal of Nuclear Materials, Vol. 417, (2011), p. 241-244.

[12] R.K. Nanstad, D.A. McClintock, D.T. Hoelzer, L. Tan and T.R. Allen, Journal of Nuclear Materials, Vol. 392, (2009), p. 331-340.

[13] J. Bentley, D.T. Hoelzer, D.W. Coffey and K.A. Yarborough, Microscopy and Microanalysis, Vol. 10, Supplement 2, (2004), p. 662-663.

[14] M.K. Miller, K.F. Russell and D.T. Hoelzer, Journal of Nuclear Materials, Vol. 351, (2006), p. 261-268.

[15] M.K. Miller, D.T. Hoelzer and K.F. Russell, Materials Science Forum, Vol. 654-656, (2010), p. 23-28.

[16] X.L. Wang, C.T. Liu, U. Keiderling, A.D. Stoica, L. Yang, M.K. Miller, C.L. Fu, D. Ma and K An, Journal of Alloys and Compounds, Vol. 529, (2012), p. 96-101.

[17] M.K. Miller and D.T. Hoelzer, Journal of Nuclear Materials, Vol. 418, (2011), p. 307-310.

[18] A. Certain, S. Kuchibhatla, V. Shutthanandan, D.T. Hoelzer and T.R. Allen, Journal of Nuclear Materials, Vol. 434, (2013), p. 311-321.

[19] Y. Wu, R.G. Odette, T. Yamamoto, J. Ciston and P. Hosemann, Fusion Semiannual Report: DOE/ER-0313/54, Vol. 54, (2013), p. 173-179.

[20] D.A. McClintock, D.T. Hoelzer, M.A. Sokolov and R.K. Nanstad, Vol. 386-388, (2009), p. 307-311.

[21] D.A. McClintock, M.A. Sokolov, D.T. Hoelzer and R.K. Nanstad, Vol. 392, (2009), p. 353-359.

[22] J.H. Kim, T.S. Byun, D.T. Hoelzer, S.W. Kim and B.H. Lee, Materials Science \& Engineering A, Vol. 559, (2013), p. 101-110.

[23] T.S. Byun, J.H. Kim, J.H. Yoon and D.T. Hoelzer, Journal of Nuclear Materials, Vol. 407, (2010), p. 78-82.

[24] Standard Test Method for Measurement of Fracture Toughness, ASTM Standard E1820-09 (2009).

[25] R.T. DeHoff, Chapter 7: Problem Solving using Quantitative Stereology, in Applied Metallography, Ed: G.F. Vander Voort, Van Nostrand Reinhold Company, New York, (1986), P. 89-99.

[26] P. Bate, Acta Materialia, Vol. 49, (2001), p. 1453-1461.

[27] I. Change and Y. Zhao, ed., Advances in Powder Metallurgy: Properties, Processing and Applications, Woodhead Publishing Limited, Cambridge, UK, (2013). 
[28] M.K. Miller, D.T. Hoelzer, E.A. Kenik and K.F. Russell, Intermetallics, Vol. 13, (2005), p. $387-392$.

[29] M.K. Miller, E.A. Kenik, K.F. Russell, L. Heatherly, D.T. Hoelzer and P.J. Maziasz, Materials Science and Engineering A, Vol. 353, (2003), p. 140-145.

[30] M.K. Miller and C.M. Parish, Materials Science and Technology, Vol. 27, No. 4, (2011), p. 729-734.

[31] J.H. Kim, T.S. Byun, D.T. Hoelzer, S.W. Kim and B.H. Lee, Materials Science \& Engineering A, Vol. 559, (2013), p. 111-118.

[32] J. Bentely and D.T. Hoelzer, Microscopy and Microanalysis, Vol. 14, (2008), p. 14161418.

[33] M.J. Alinger, Ph.D. Thesis, University of Santa Barbara, USA, 2004.

[34] M.A. Sokolov, D.T. Hoelzer, R.E. Stoller and D.A. McClintock, Journal of Nuclear Materials, Vol. 367-370, (2007), p. 213-216.

[35] R. Chaouadi, External Report SCK-CEN-ER-190, FP-7 GETMAT, (2011), p. 1-18.

[36] R. Chaouadi, M. Ramesh and S. Gavrilov, Journal of Nuclear Materials, Vol. 442, (2013), p. $425-433$.

[37] I.S. Kim, B.Y Choi, C.Y. Kang, T. Okuda, P.J. Maziasz and K. Miyahara, ISIJ International, Vol. 43, No. 10, (2003), p. 1640-1646.

[38] G.W. Geil, N.L. Carwile and T.G. Digges, Journal of Research of the National Bureau of Standards, Vol. 48, No. 3, (1952), p. 193-200.

[39] E.D Hondros and L.E.H. Stuart, Philosopical Magazine, Vol. 17, No. 148, (1968), p. 711727.

[40] E.D. Hondros, Metal Science Journal, Vol. 1, (1967), p. 36-39.

[41] C.L. Briant, S.K. Banergi and A.M. Ritter, Metallurgical Transactions A, Vol. 13A, (1982), p. 1939-1950.

[42-38]M.J. Alinger, G.R. Odette and G.E. Lucas, Journal of Nuclear Materials, Vol. 307-311, (2002), p. 484-489.

[43] M. Klimiankou, R. Lindau and A. Möslang, Journal of Nuclear Materials, Vol. 367-370, (2007), p. 173-178.

[44] J.S. Park, Z. Zhang, H. Sharma, P. Kenesei, D.T. Hoelzer, M. Li and J. Almer, Journal of Materials Research, Vol. 30, No. 9, (2015), p. 1380-1391.

[45] N.J. Cunningham, Y. Wu, A. Etienne, E.M. Haney, G.R. Odette, E. Stergar, D.T. Hoelzer, Y.D. Kim, B.D. Wirth and S.A. Maloy, Journal of Nuclear Materials, Vol. 444, (2014), p. 35-38. 
[46] A. Hirata, T. Fujita, C.T. Liu and M.W. Chen, Acta Materialia, Vol. 60, (2012), p. 56865696.

[47] P. Unifantowicz, T. Płocińsk, C.A. Williams, R. Schäublin and N. Baluc, Journal of Nuclear Materials, Vol. 442, (2013), p. 158-163.

[48] Q. Guo-Zheng, "Characterization for Dynamic Recrystallization Kinetics Based on StressStrain Curves", in Recent Developments in the Study of Recrystallization, P. Wilson, ed., InTech Publisher, (2013), DOI: 10.5772/56031, p. 61-88. 
(a)
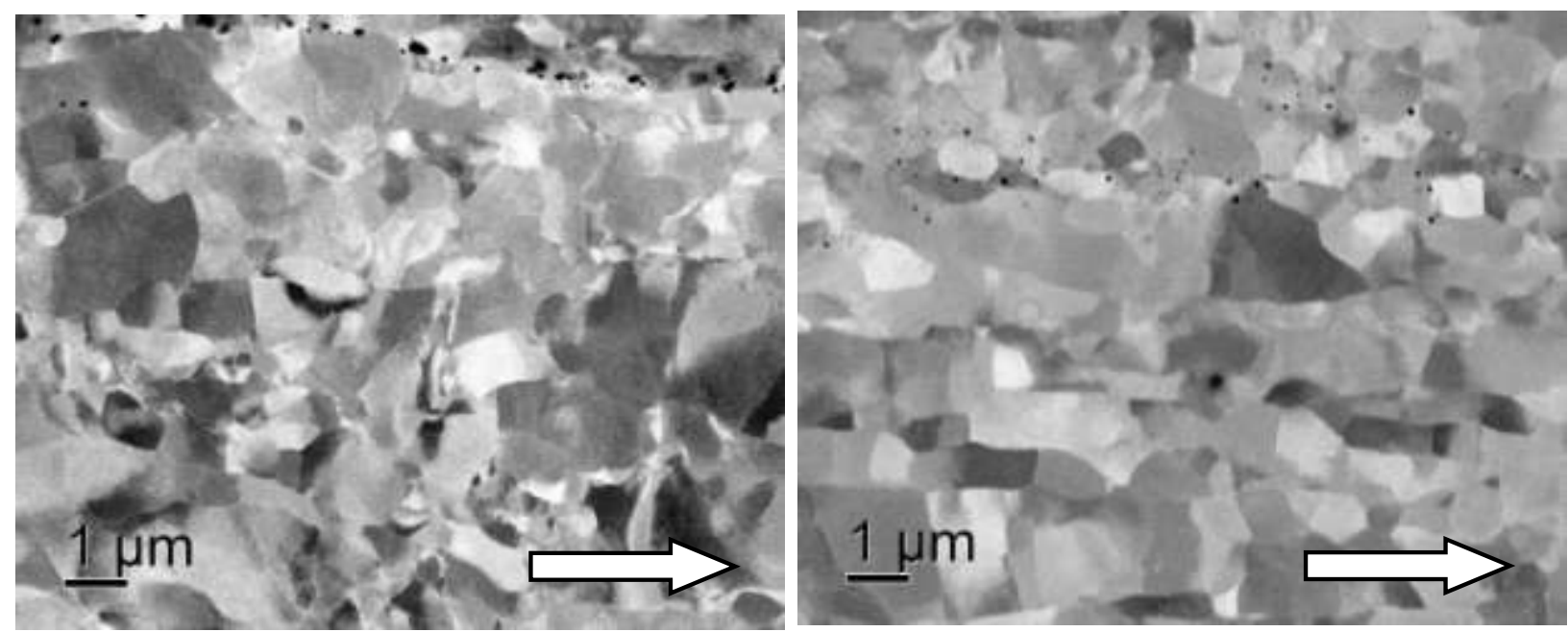

(c)

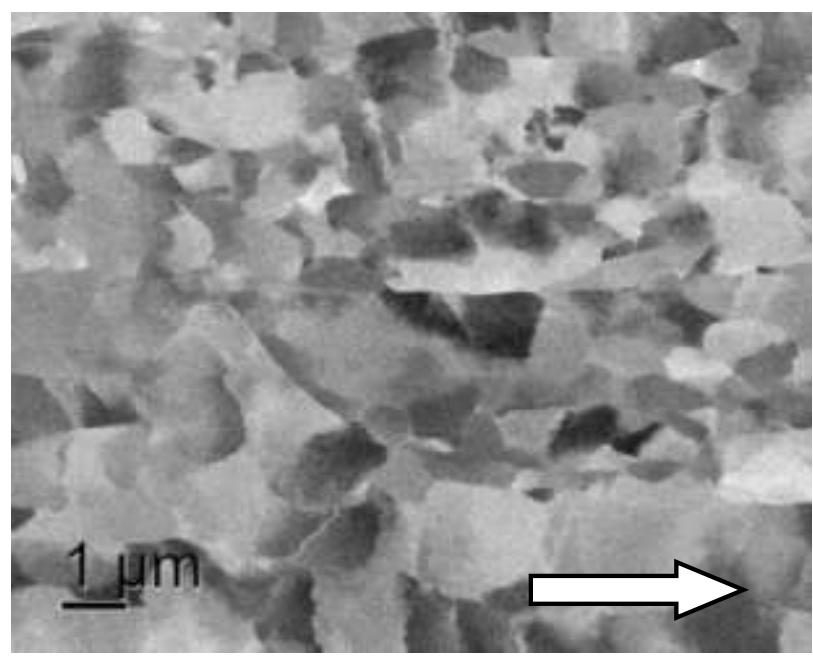

Figure 1. BSE micrographs showing the grain structures of the SM heats: (a) SM170, (b) SM185 and (c) SM200. (Arrows show extrusion and rolling directions.)

(b)

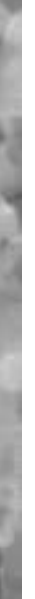


(a)

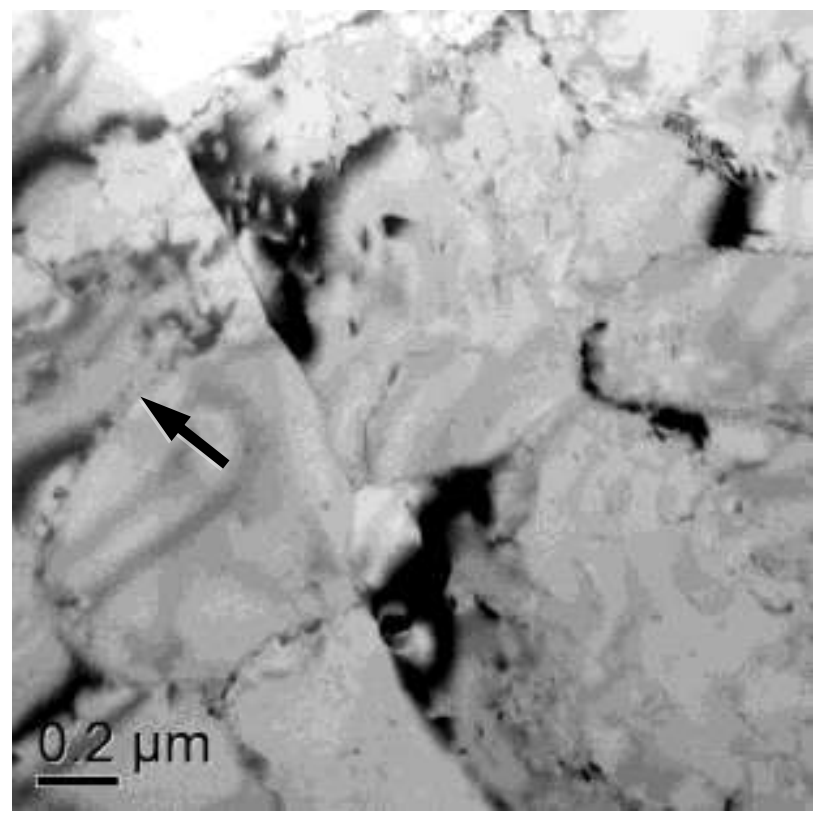

(b)

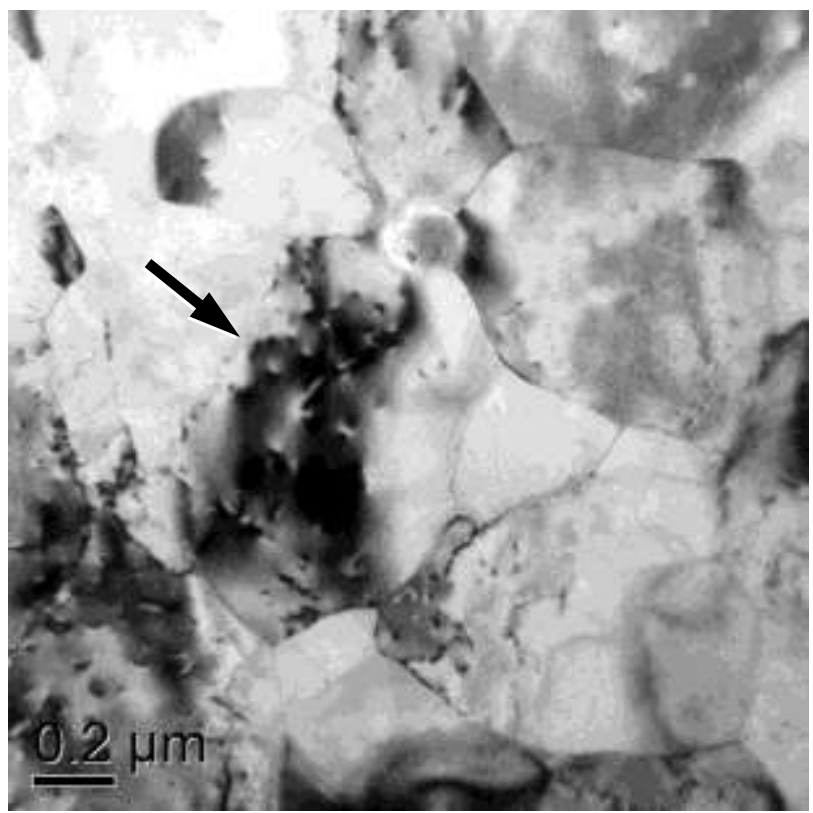

(c)

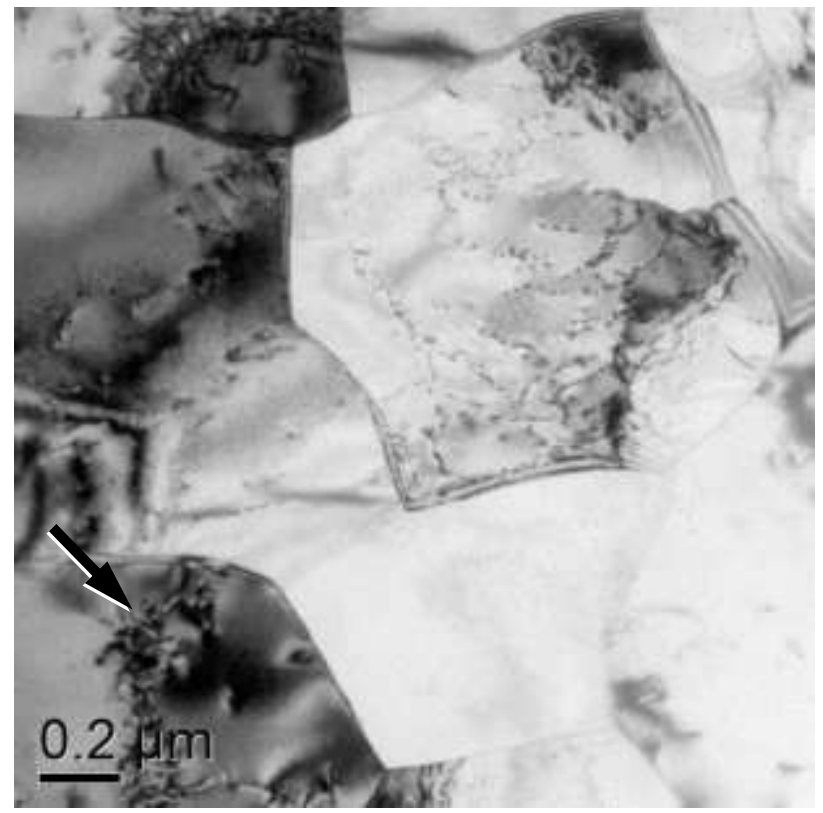

Figure 2. TEM BF micrographs showing the microstructures of the SM heats: (a) SM170, (b) SM185 and (c) SM200. 
(a)

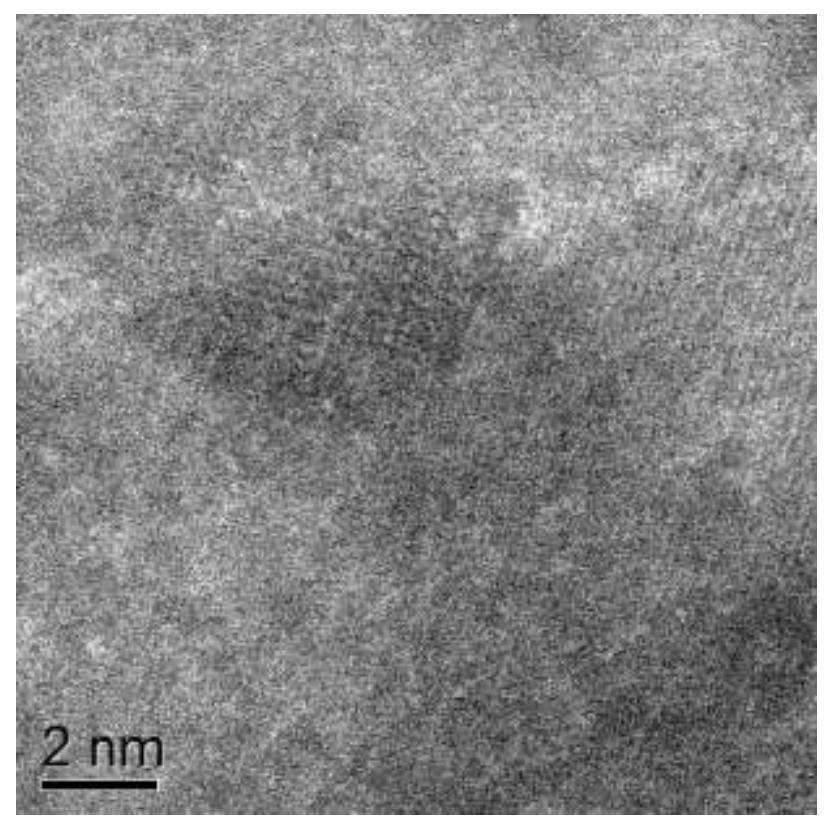

(b)

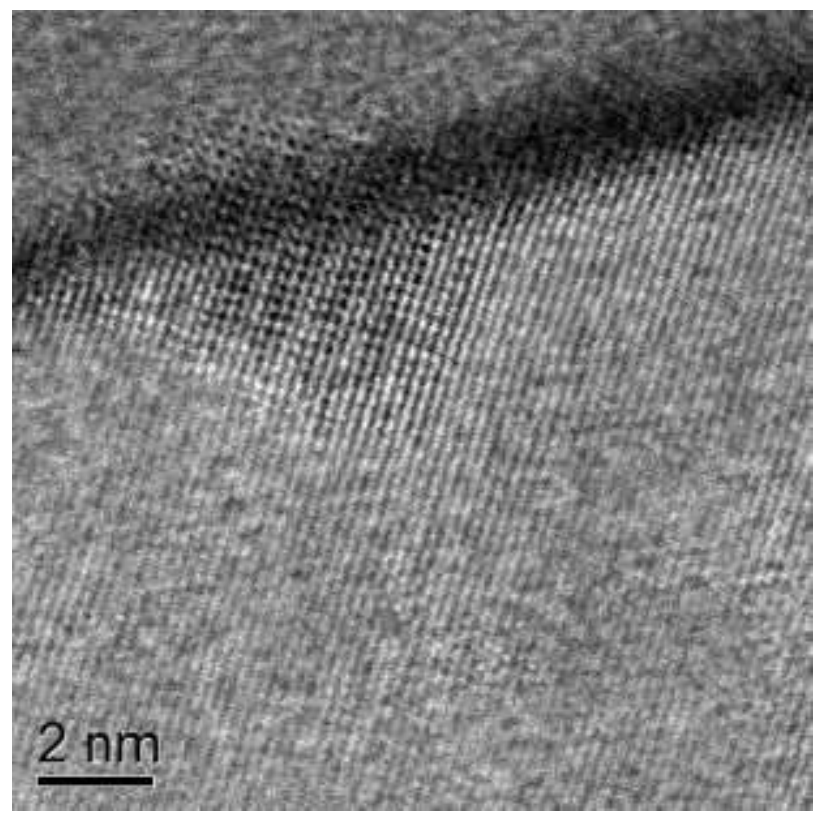

(c)

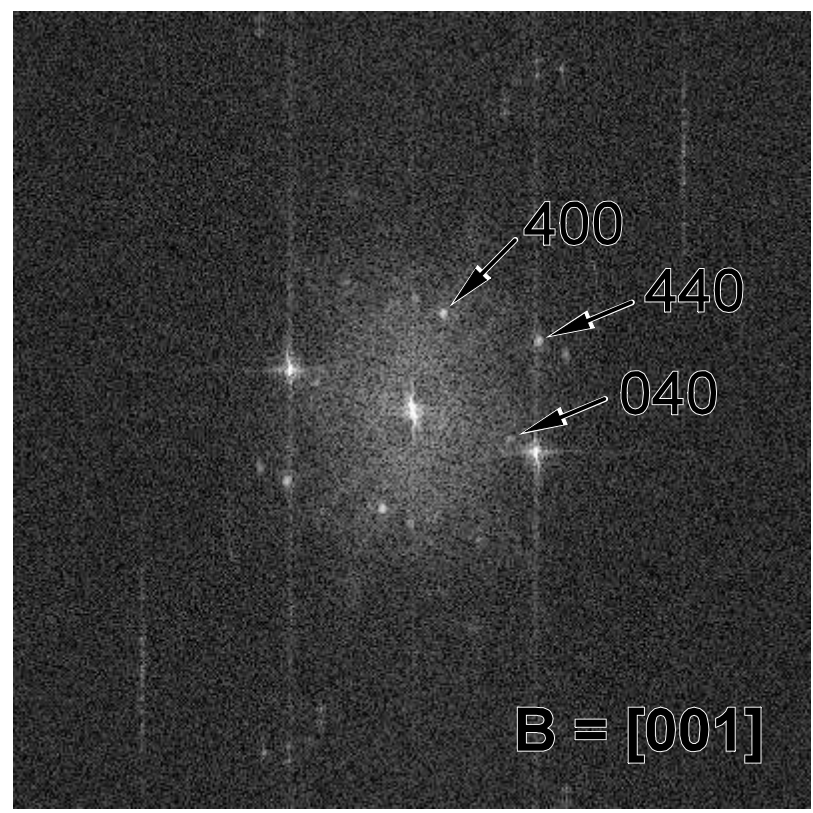

Figure 3. High resolution ACEM analysis of grain boundary particle observed in SM200: (a) BF STEM, (b) DF-STEM and (c) FFT pattern of the region. 
(a)

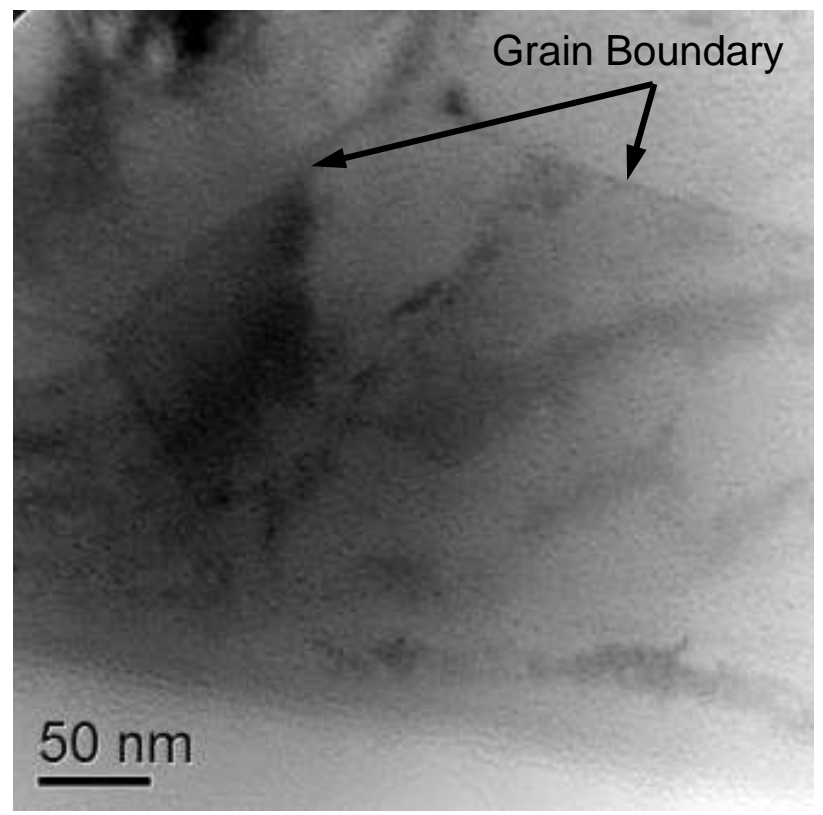

(b)

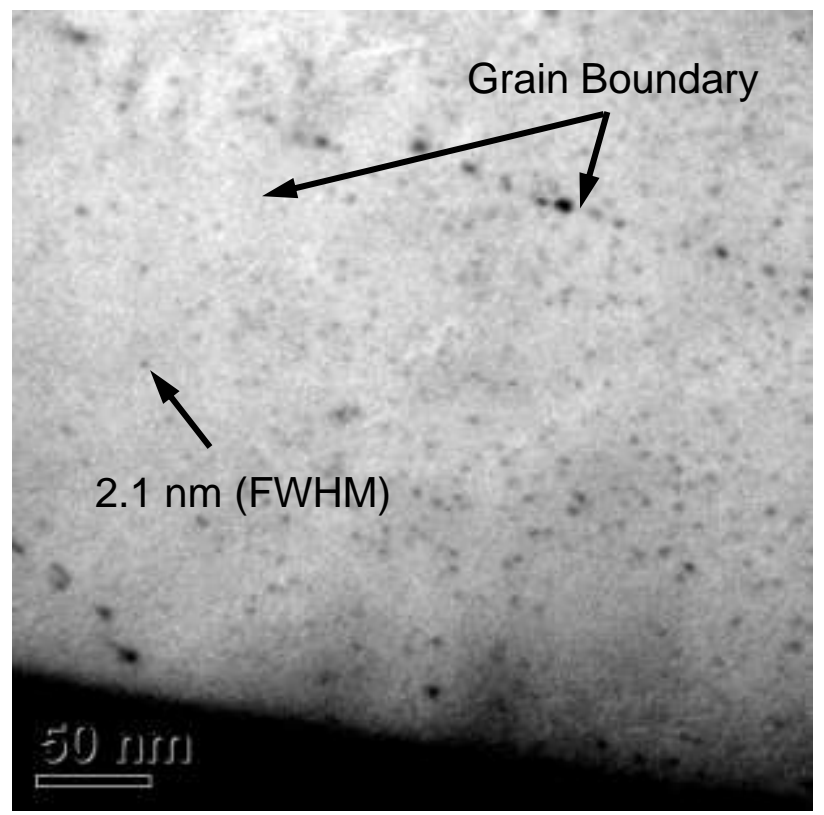

(c)

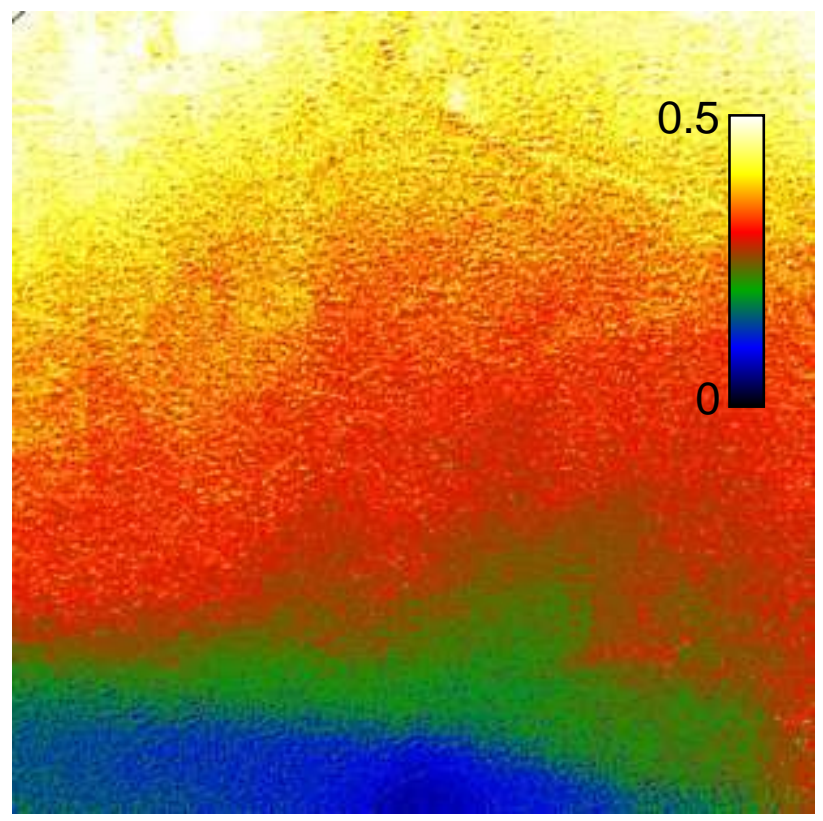

Figure 4. EFTEM analysis of SM170 near the thin foil edge: (a) Unfiltered image, (b) Fe-M jump-ratio map and (c) $\mathrm{t} / \lambda$ thickness map $(\lambda \cong 140 \mathrm{~nm} ; 0.5 \lambda \cong 70 \mathrm{~nm})$. 
(a)
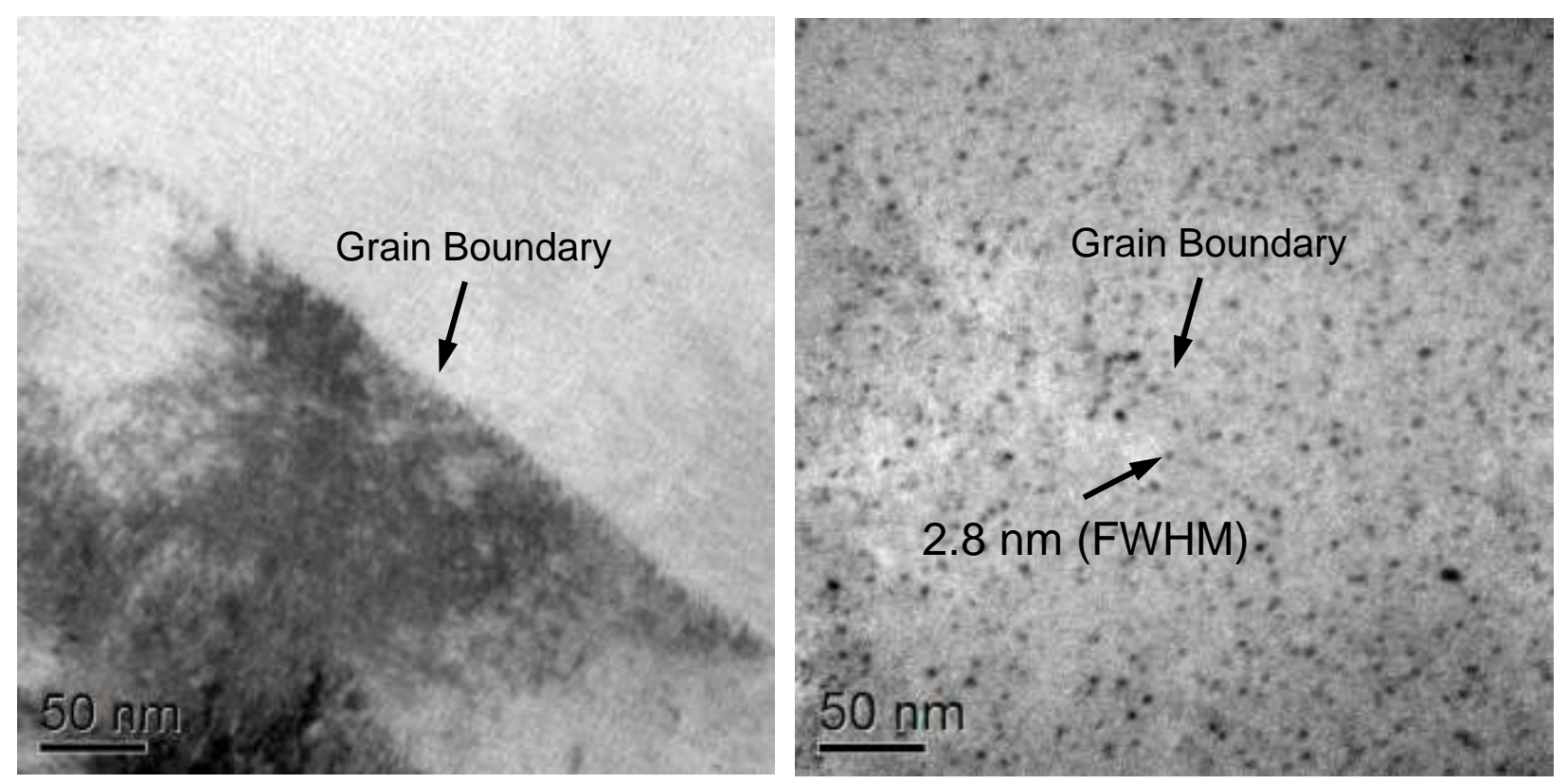

(c)

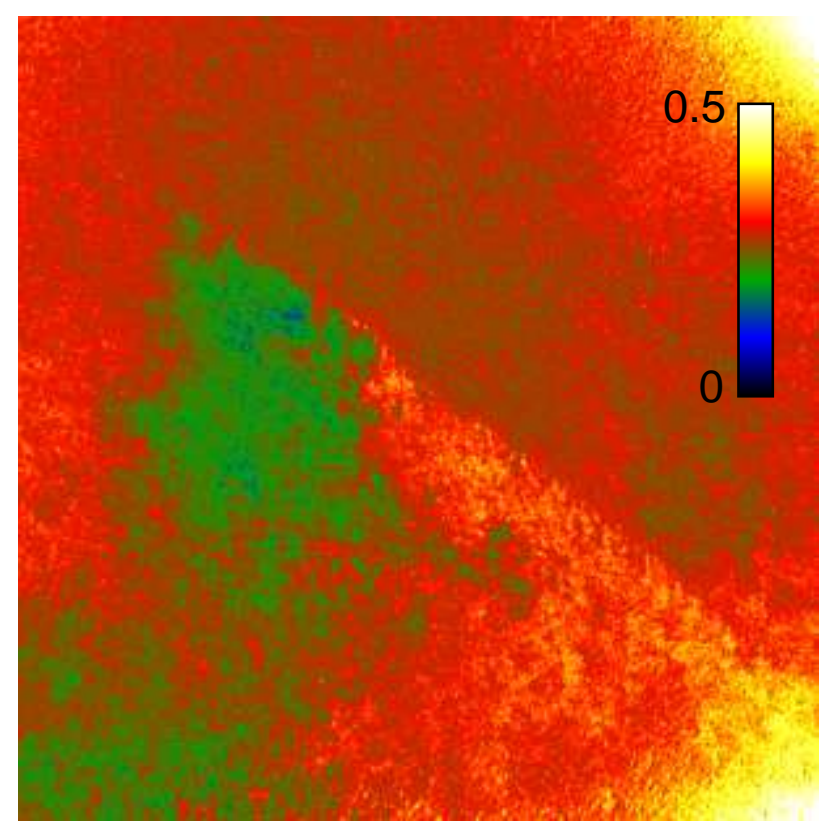

Figure 5. EFTEM analysis of SM185 near the thin foil edge: (a) Unfiltered image, (b) Fe-M jump-ratio map and (c) $\mathrm{t} / \lambda$ thickness map $(\lambda \cong 140 \mathrm{~nm} ; 0.5 \lambda \cong 70 \mathrm{~nm})$. 
(a)

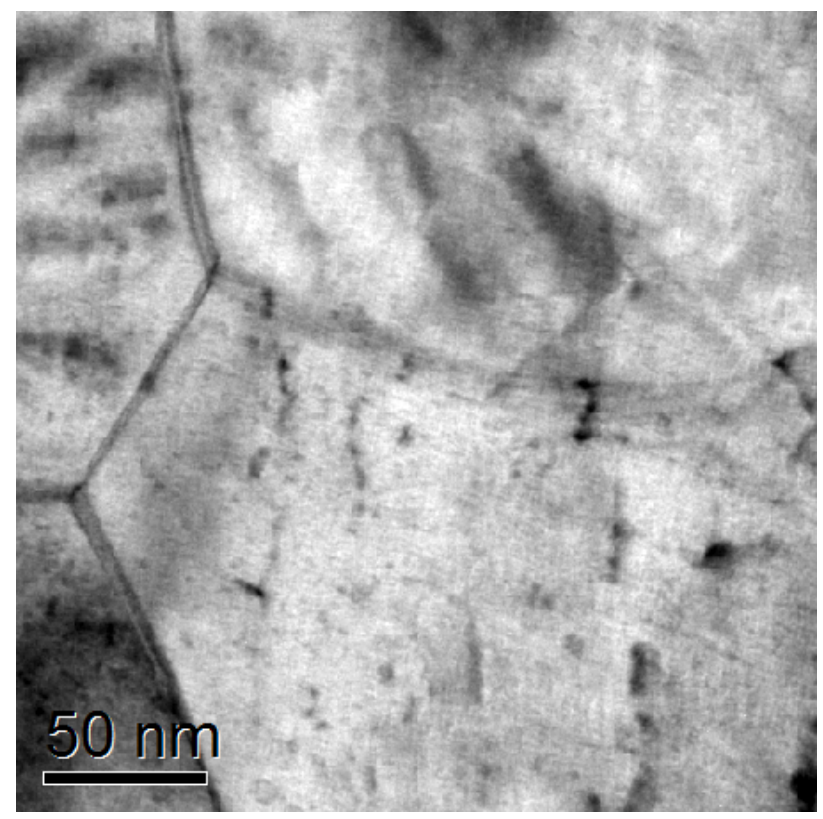

(b)

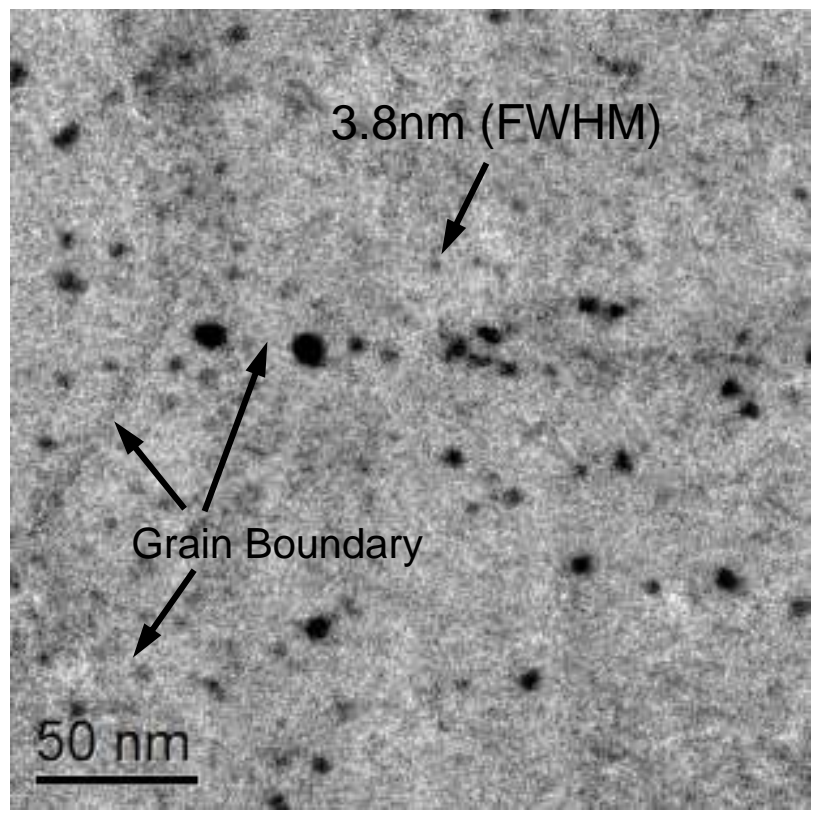

(c)

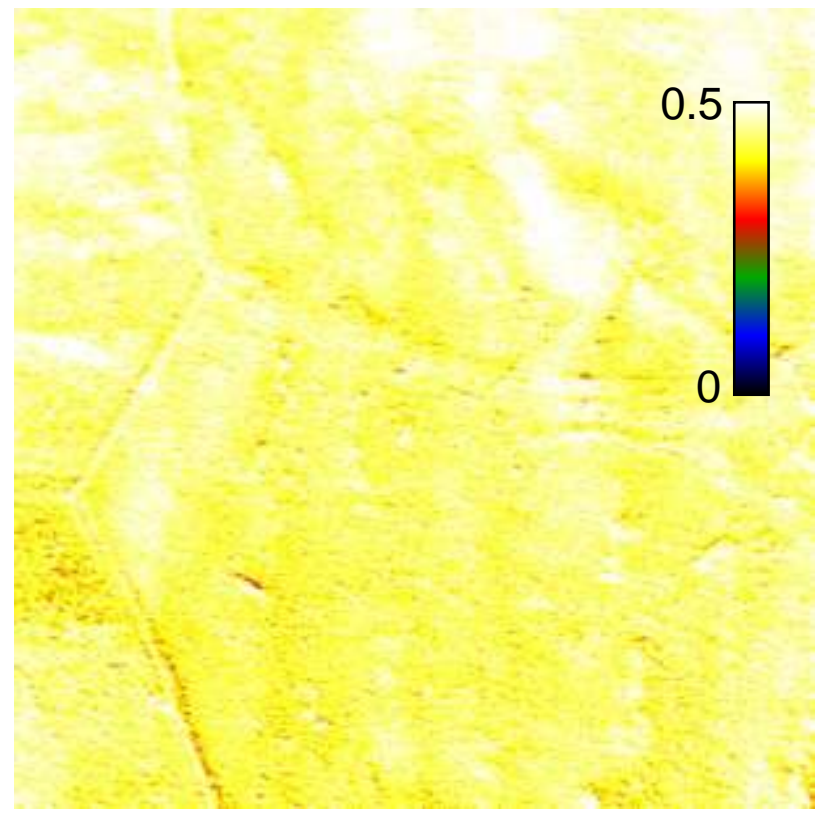

Figure 6. EFTEM analysis of SM200 near the thin foil edge: (a) Unfiltered image, (b) Fe-M jump-ratio map and (c) $\mathrm{t} / \lambda$ thickness map $(\lambda \cong 140 \mathrm{~nm} ; 0.5 \lambda \cong 70 \mathrm{~nm})$. 


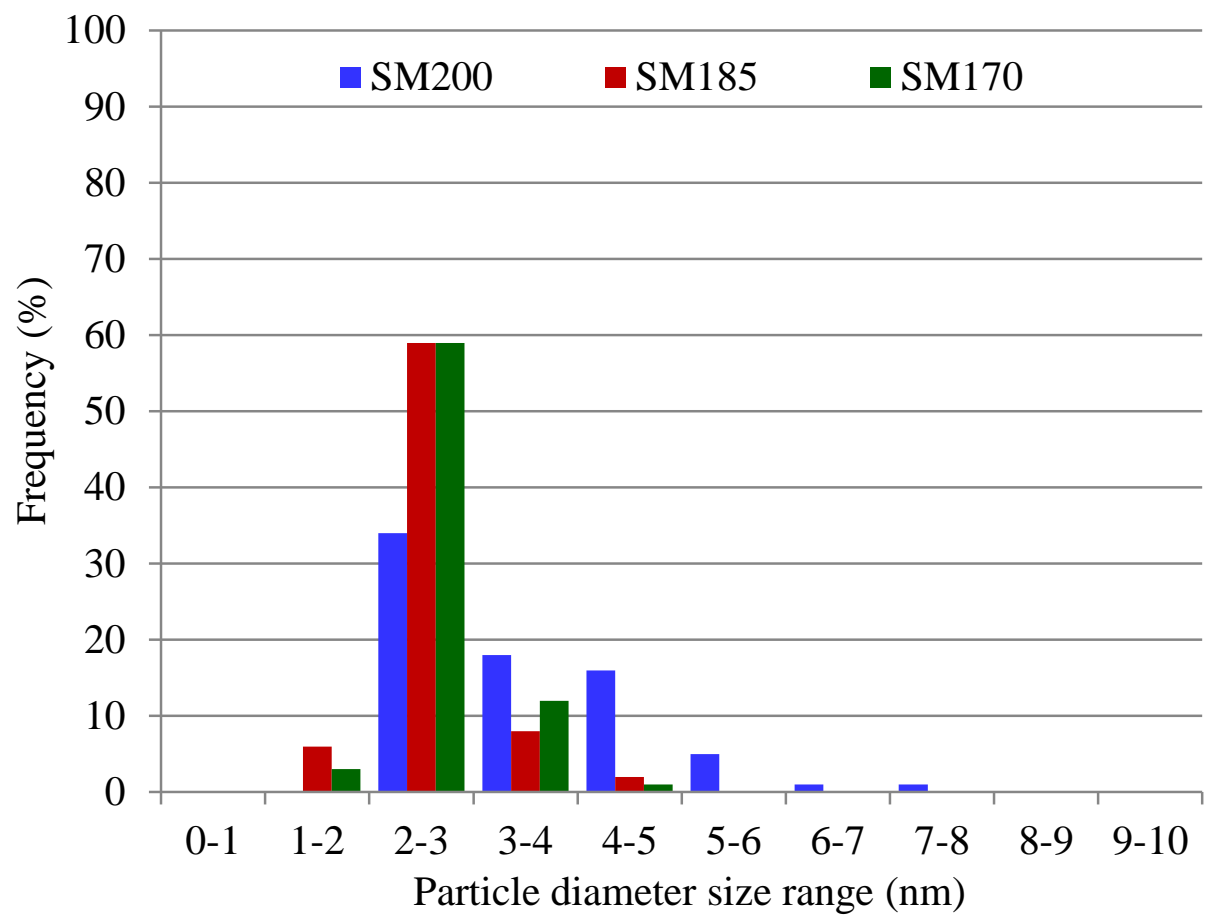

Figure 7. Comparison of the size distribution of nanoclusters obtained for SM170, SM185 and SM200. 
(a)

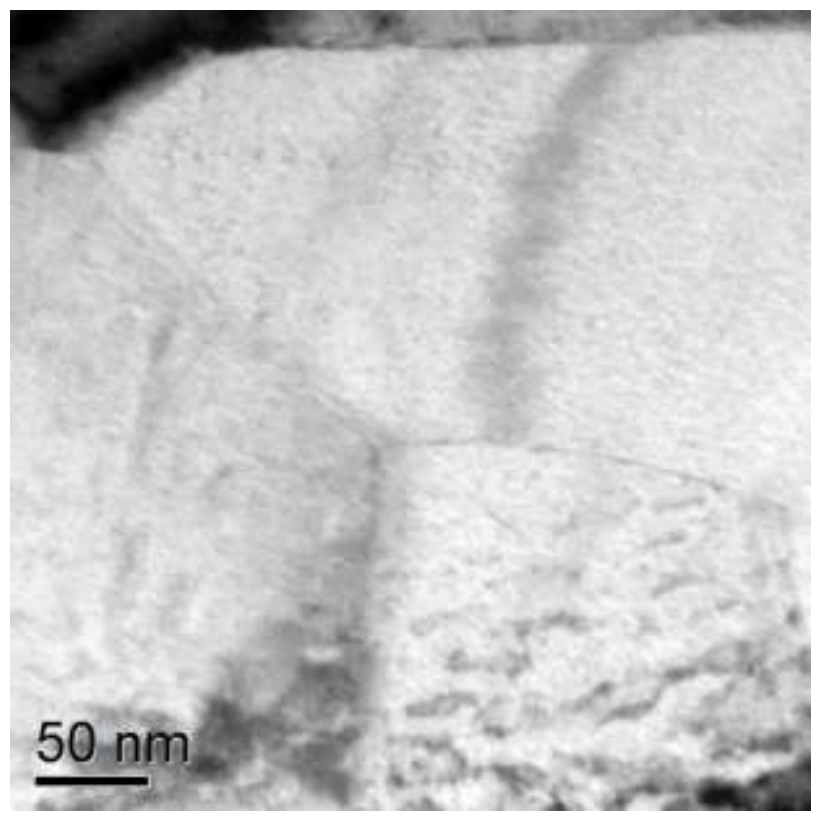

(b)

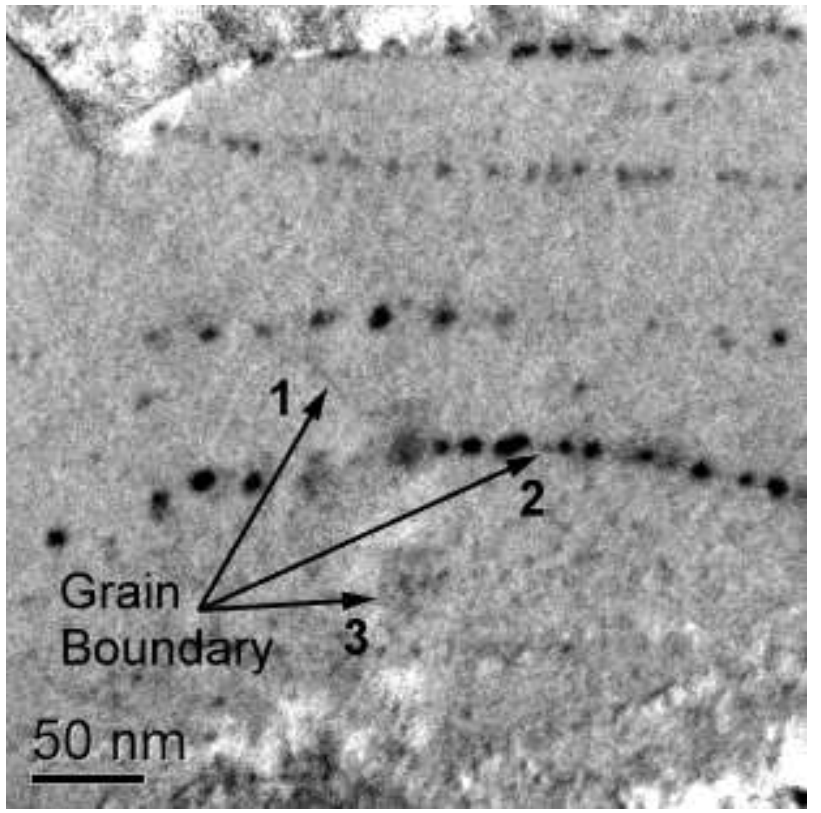

Figure 8. (a) Unfiltered image and (b) Fe-M jump-ratio map showing the presence of larger NC and oxide particles on some grain boundaries $\left({ }^{\#} 2\right)$ but not on other grain boundaries $\left({ }^{\#} 1\right.$ and ${ }^{\#} 3$ ) that were observed in SM200.

(a)

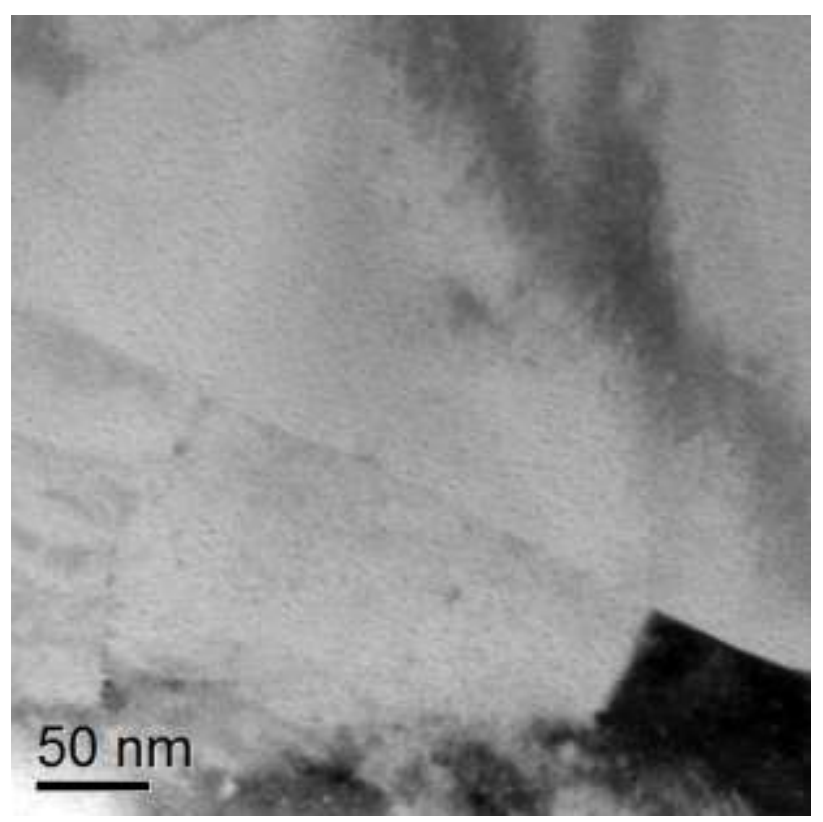

(b)

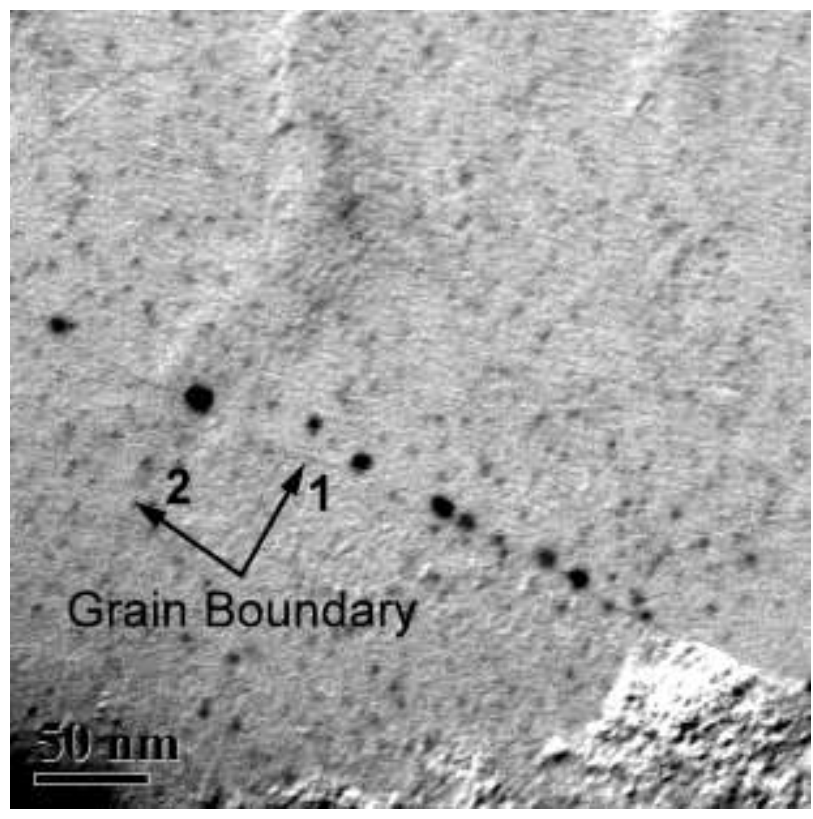

Figure 9. (a) Unfiltered image and (b) Fe-M jump-ratio map showing the presence of larger NC and oxide particles on grain boundary $\left({ }^{\#} 1\right)$ but not on grain boundary $\left({ }^{\#} 2\right)$ that were observed in SM185. 


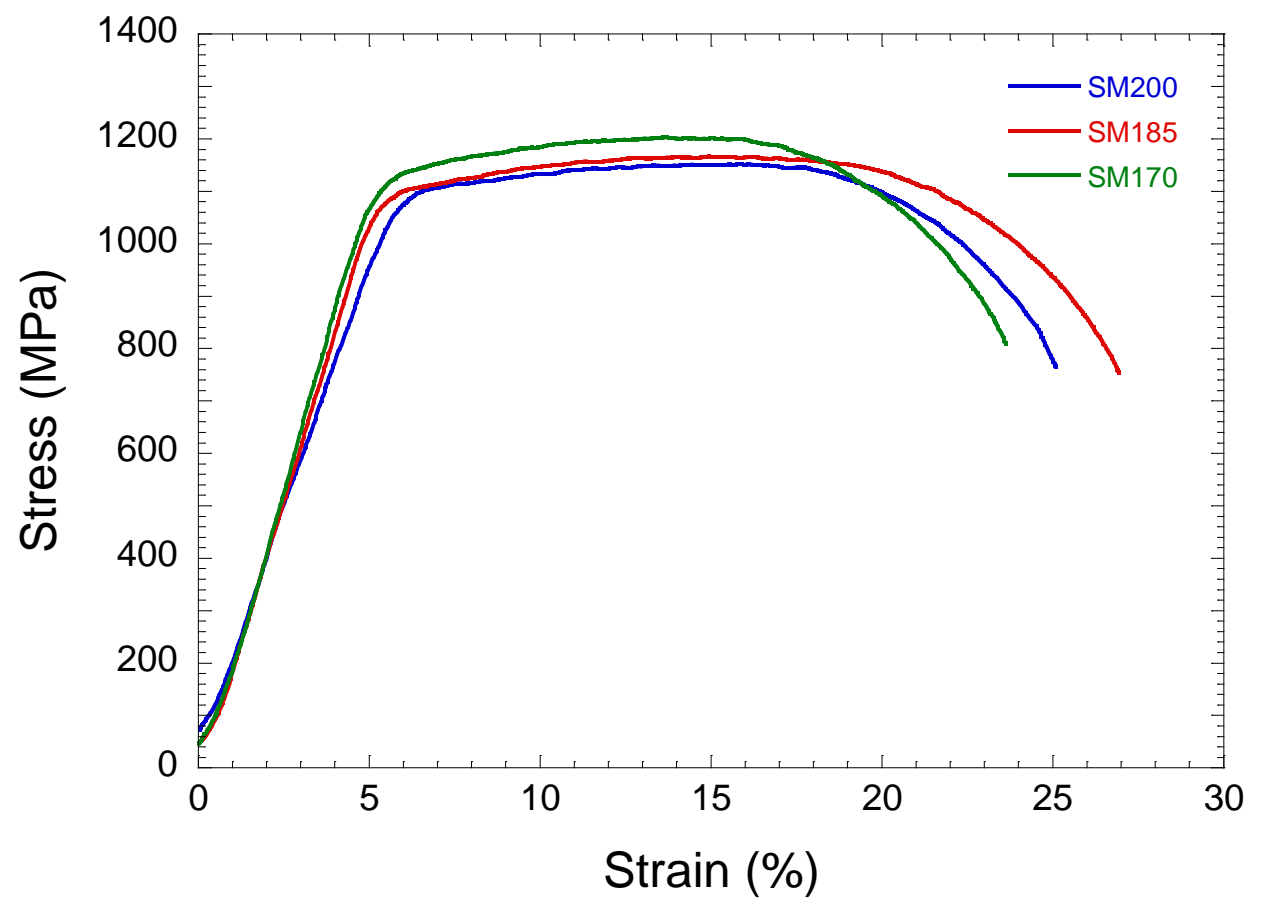

Figure 10. Comparison of stress strain curves from tensile tests at room temperature for SM170, SM185 and SM200. 
(a)

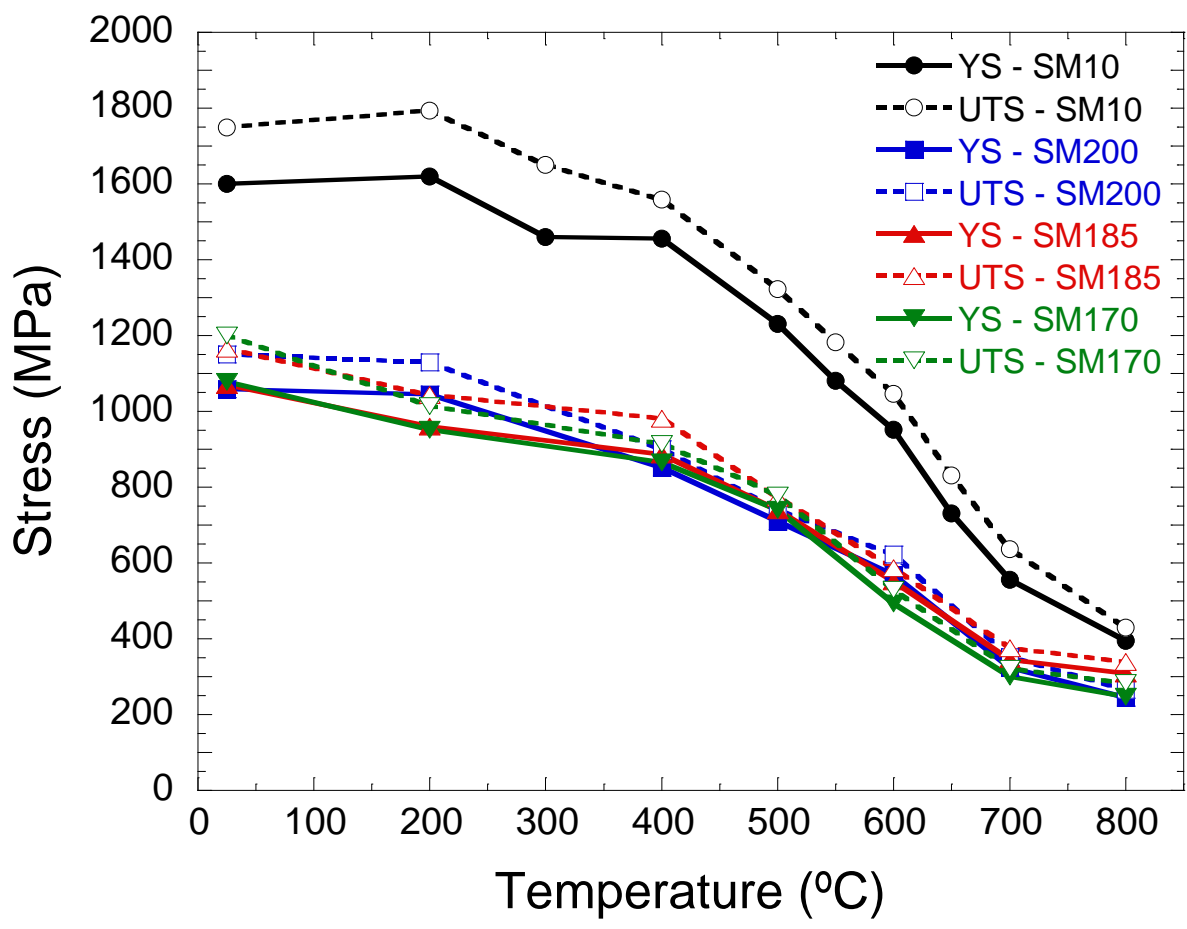

(b)

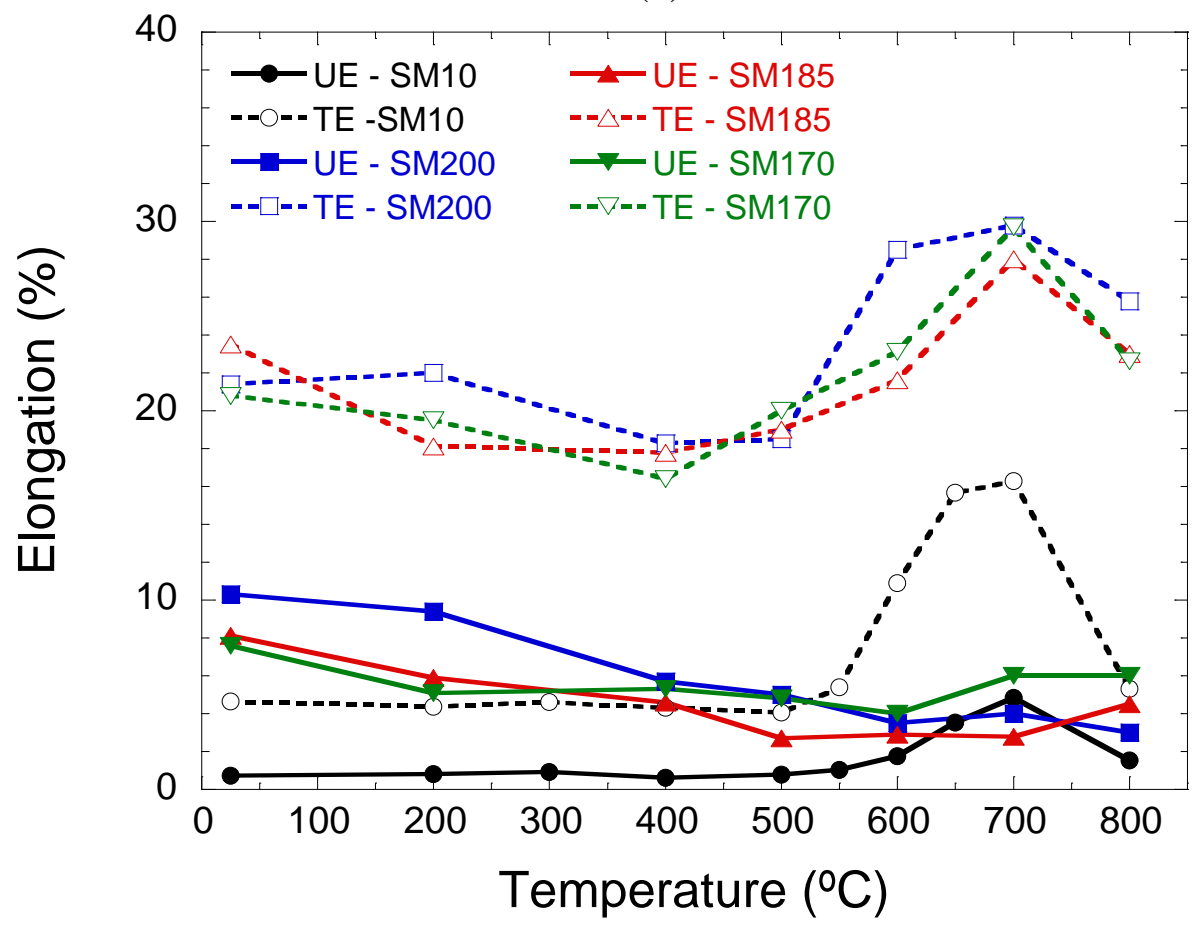

Figure 11. Results showing the temperature dependence of tensile properties from $25^{\circ} \mathrm{C}$ to $800^{\circ} \mathrm{C}$ for the three SM heats compared to 14YWT-SM10: (a) yield (YS) and ultimate tensile (UTS) stresses and (b) uniform (UE) and total (TE) elongations as a function of temperatures. 


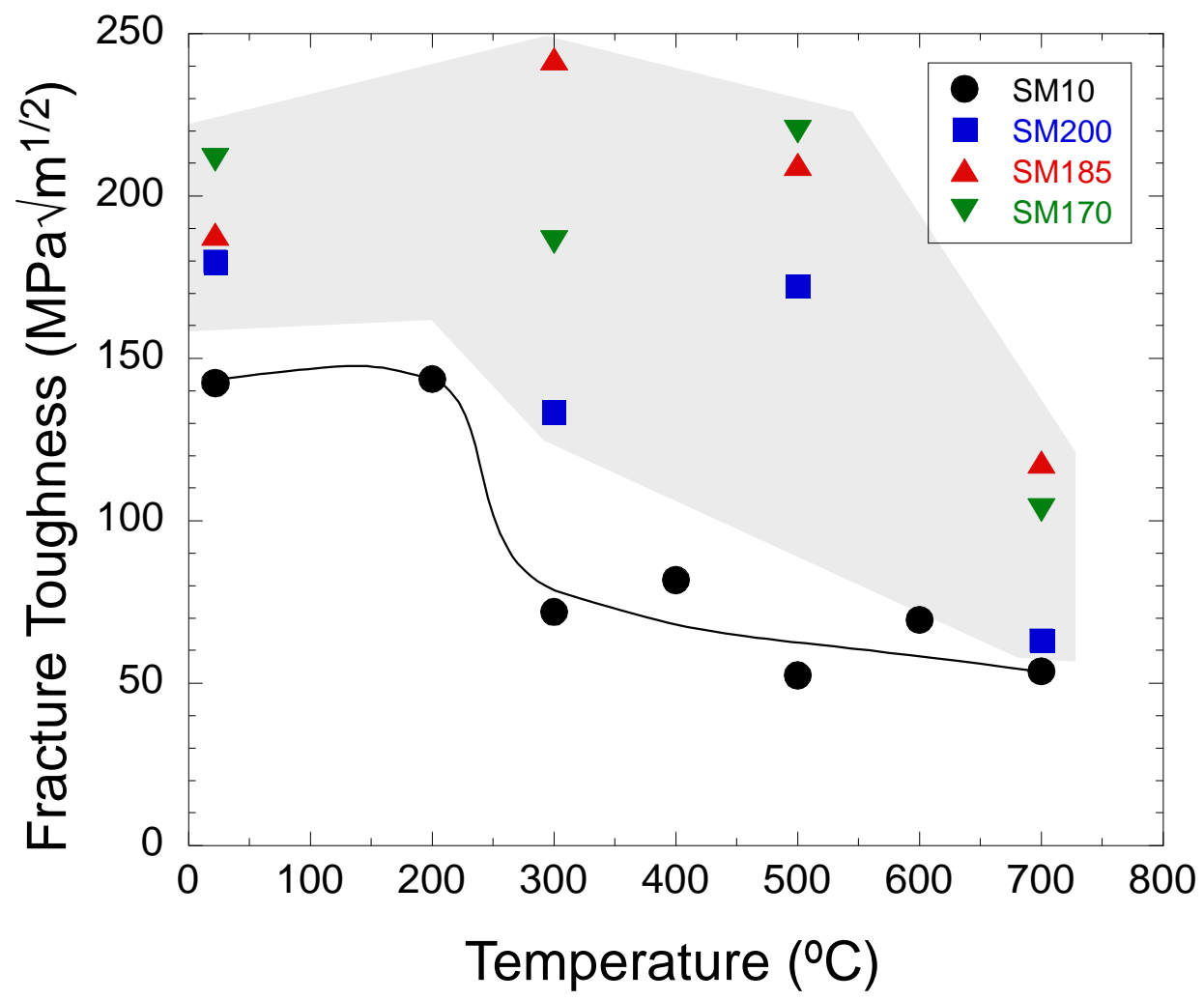

Figure 12. Comparison of the high-temperature fracture toughness between the three SM heats and the SM10 heat of 14YWT. 